TI 2012-004/3

Tinbergen Institute Discussion Paper

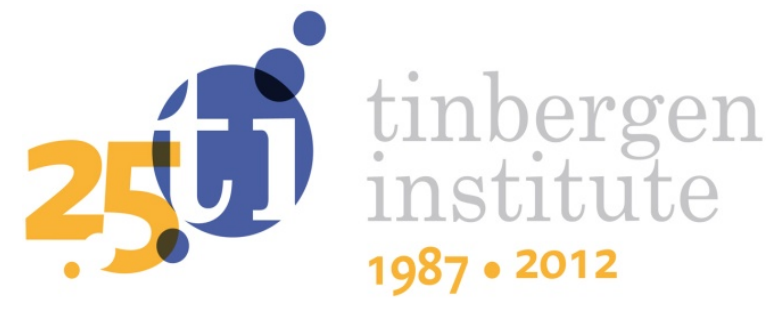

\title{
Who is at the Top? Wealth Mobility over the Life Cycle
}

Stefan Hochguertell

Henry Ohlsson ${ }^{2}$

' Faculty of Economics and Business Administration, VU University Amsterdam, and Tinbergen Institute;

2 Department of Economics, Uppsala University, and Uppsala Center for Fiscal Studies (UCFS). 
Tinbergen Institute is the graduate school and research institute in economics of Erasmus University Rotterdam, the University of Amsterdam and VU University Amsterdam.

More TI discussion papers can be downloaded at http://www.tinbergen.nl

Tinbergen Institute has two locations:

Tinbergen Institute Amsterdam

Gustav Mahlerplein 117

1082 MS Amsterdam

The Netherlands

Tel.: +31(0)205251600

Tinbergen Institute Rotterdam

Burg. Oudlaan 50

3062 PA Rotterdam

The Netherlands

Tel.: +31(0)10 4088900

Fax: $+31(0) 104089031$

Duisenberg school of finance is a collaboration of the Dutch financial sector and universities, with the ambition to support innovative research and offer top quality academic education in core areas of finance.

DSF research papers can be downloaded at: http://www.dsf.nl/

Duisenberg school of finance

Gustav Mahlerplein 117

1082 MS Amsterdam

The Netherlands

Tel.: +31(0)20 5258579 


\title{
Who is at the top? Wealth mobility over the life cycle*
}

\author{
Stefan Hochguertel Henry Ohlsson
}

16 January 2012

\begin{abstract}
Who is wealthy? This paper presents empirical estimates of household movements into and out of the top percents of the wealth distribution over individual life cycles. There are life-cycle motives and precautionary motives for wealth accumulation. The opportunities to accumulate wealth create incentives for education, work effort, and entrepreneurship. We would expect considerable wealth mobility over the life cycle if the life-cycle motives and incentives to accumulate are strong and affect behavior. The data are from an administrative Swedish source that retains wealth information from tax registers. The data are unique, they follow a large sample of households over almost 40 years. There is substantial mobility when we follow individual households over long enough time spans. We find that wealth mobility increased until the end of the 1980s and then started to decrease. Age-wealth probability profiles are consistent with life-cycle motives for wealth accumulation. There are also limited precautionary motives for wealth accumulation when households experience income uncertainty.
\end{abstract}

Keywords: intragenerational wealth mobility, wealth durations, life-cycle motives, precautionary motives, panel data

EconLit subject descriptors: D140, D310, D910, H240

Stefan Hochguertel, Department of Economics, VU University Amsterdam and Tinbergen Institute, The Netherlands, and Uppsala Center for Fiscal Studies (UCFS), Department of Economics, Uppsala University, Sweden, <s.hochguertel@vu.nl>

Henry Ohlsson, Department of Economics, Uppsala University and Uppsala Center for Fiscal Studies (UCFS), Department of Economics, Uppsala University, Sweden, < henry.ohlsson@ nek.uu.se> 
*We are grateful for financial support from the Nordic Tax Research Council. This paper is a revised version of parts of "Wealth mobility and dynamics over entire individual working life cycles" European Central Bank Working Paper No 1301, 2011. Helpful comments and suggestions on previous versions from Martin Browning, Aura Leulescu, Daniel Waldenström, participants at the 2009 Danish Microeconometric Network Meeting, the 2010 International Conference on Panel Data, the 2010 Joint BCL/ECB Conference on Household Finance and Consumption, and seminar participants at VU University, Amsterdam; CEPAR, UNSW, Sydney; and Uppsala University are gratefully acknowledged. Some of the work was done when Ohlsson enjoyed the hospitality of LEM, Université Panthéon-Assas, Paris II and some when Ohlsson enjoyed the hospitality of School of Economics, UNSW, Sydney during a sabbatical. Financial support for the sabbatical from the Wenner-Gren Foundations is gratefully acknowledged. 


\section{Introduction}

Personal wealth is highly concentrated both within countries and between countries (Davies, 2008). Davies et al. (2008) reports that households in the top one percent of the wealth distribution hold 33 percent of total private wealth in the United States. Corresponding figures are 35 percent for Switzerland, 29 percent for Denmark, 23 percent for the United Kingdom, and 21 percent for France. Ohlsson et al. (2008) reports a top one percent share of total wealth of 18 percent in Sweden.

Who is wealthy? Is being wealthy temporary or permanent? People accumulate wealth during their working lives for consumption during retirement. This is the traditional life-cycle motive for savings in the tradition of Modigliani and Brumberg (1954). Those who save accumulate wealth with age in an absolute sense. They also move through the wealth distribution and improve their position in the wealth ranking. How important are life-cycle motives driven by consumptions smoothing for wealth accumulation? There are also precautionary motives for wealth accumulation (Leland, 1968). How important are precautionary motives?

The opportunities to accumulate wealth, in turn, create incentives for education, work effort, and entrepreneurship. We would expect considerable wealth mobility over the life cycle if the life-cycle motives and incentives to accumulate are strong and affect behavior. But to what extent is there equality of opportunity within a cohort?

The degree of intragenerational wealth mobility is important when discussing different economic issues. First, wealth accumulation is the result of choices concerning labor supply, consumption, and savings. Life-cycle models predict that individuals will accumulate wealth while working and then decumulate when retired. One set of issues concern how well the life-cycle model predicts the actual age-wealth profiles and if these profiles differ between individuals. Another issue is if controlling for other determinants of wealth reduces the observed differences in age-wealth profiles. While we can, in principle, control for education, other important determinants of wealth accumulation such as entrepreneurial ability, are inherently unobservable.

Second, wealth mobility reflects the extent to which there is equality of opportunity in a society. If there is complete equality of opportunity, the wealth of a young person will not be a good predictor of this person's wealth when middle aged. Suppose that entrepreneurship and risk taking sometimes for some yield considerable wealth increases. If wealth taxation reduces entrepreneurship and risk taking, we would then expect reduced wealth mobility. Wealth during different phases of the life cycle will be highly correlated if, on the other hand, inherited wealth is important. Inheritances are, however, very unequally distributed.

We study the mobility of individuals and households in the wealth distribution as they age and, therefore, over time. A related objective is to study other determinants of being wealthy. We expect considerable differences in the life-cycle patterns of wealth as people differ in many respects. The focus is on mobility between two possible states: being wealthy and not being wealthy. This is the im- 
portant extensive margin to study for macroeconomic aggregates and from a public finance perspective.

The longitudinal micro data set we use in this paper is drawn from public registers. It spans close to four decades. This is a feature that, to our knowledge, is unique in the world. The data allow us to track individual households' wealth transitions on a year-by-year basis.

The administrative nature of our panel data implies that we do not face any of the problems surveys do. This is the particular strength. Our data base, however, only captures the households that pay wealth taxes. This limits the analysis we can provide. We can, however, study the important top of the wealth distribution.

We can assess wealth mobility over the entire life cycle. This helps overcoming an important drawback of earlier studies of intragenerational wealth mobility. Shorrocks (1978a) shows that measured mobility, and its links with a distributional assessment of inequality, directly depends on the length of the observation window.

\subsection{Previous literature on intragenerational wealth mobility}

The previous literature on intragenerational wealth mobility includes Hurst et al. (1998), Jianakoplos and Menchik (1997), Keister (2005), and Steckel and Krishnan (2006) who all study wealth mobility in the United States. Jappelli and Pistaferri (2000) study wealth mobility in Italy. Klevmarken et al. (2003) and Klevmarken (2004) are among the previous papers on wealth mobility in Sweden.

These studies are based on wealth observations, in the time dimension, for 2-4 years. Wealth mobility is studied by comparing individual households' positions in the wealth distribution, in most cases, 5-7 years apart. Sometimes the time span is down to 2 years, sometimes up to $10-15$ years apart. The sample sizes are quite small, in the cross-section dimension there are observations for 1,000-5,000 households. Wealth mobility is defined as movements between quartiles, quintiles, or deciles in the wealth distribution.

Most studies find that the probabilities to stay poor or to remain wealthy are comparatively high. Wealth mobility is predominantly high in the middle of the wealth distribution. The previous literature consists of single country studies. Klevmarken et al. (2003) is the only exception, it compares wealth mobility in the United States and Sweden. Contrary to what many might have conjectured, Klevmarken et al. (2003) find that wealth mobility in Sweden is as high as in the US.

Quadrini (2000) differs from other studies by separating the wealth mobility of business owners (self-employed) from that of other households. He finds that households owning businesses are more likely to move upwards in the wealth distribution than other households. The entrepreneurial households, in this sense, show more upward wealth mobility.

The previous literature is, however, limited by the small number of observations. In the time dimension, the few observations for specific individuals for different years can only account for very limited parts of the individual's life cycle. In 
the cross section dimension, the few observations of different individuals for specific years mean that observations can only be grouped into a few quantiles. This means that the measure of mobility becomes imprecise when mobility is defined as movements between quantiles. These limitations also reduce the possible choices of empirical methods to study mobility. In addition, the previous literature is based on survey data. Surveys tend not to do so well in covering the top percents of the wealth distribution.

\subsection{Our contribution}

We believe that we can deal with these shortcomings of the previous mobility literature. The data available to us are from the LINDA data base, an administrative source from Statistics Sweden. This data base provides long individual time series, many individuals, and the top percents of the wealth distribution are well documented. This enables us to improve considerably on the analysis of wealth mobility.

The LINDA data base sampled slightly more than 3 percent of the Swedish population and also includes the household members of the sampled individuals. There are 300,000 households and 700,000 individuals in this data base. We can follow a considerable part of individual life cycles for many. There are close to 40 annual observations for some individuals.

The key variables we use are derived from annual taxable net wealth at the individual level and at the household level from 1968 to $2005 .{ }^{1}$ The wealth tax was repealed from 2007. A main advantage with this data set is that for those who did pay wealth taxes there are very precise wealth measurements based on third party reporting available. A disadvantage is that wealth information in the register data is only available for those whose taxable wealth exceeded the high tax exemption levels. The Tax Agency was only allowed to keep the wealth data for those who paid the tax. This means that our measure of wealth mobility is very closely related to whether or not the individual pays wealth taxes.

Wealth mobility is interpreted as the movements in and out of the top percents of the wealth distribution over time and, also, movements over time within the top percents. ${ }^{2}$ We also use an absolute real wealth measure, movements across a real wealth threshold. Macroeconomic shocks and general changes in asset prices can be expected to affect absolute wealth but not necessarily relative wealth.

\footnotetext{
${ }^{1}$ Taxable wealth at the household level was also the actual wealth tax base during the studied period.

${ }^{2}$ The paper is, therefore, related to the top wealth literature. Roine and Waldenström (2009) is a recent contribution on top wealth in Sweden. Some other studies in this literature are Kopczuk and Saez (2004) for the United States, Piketty et al. (2006) for France, Dell et al. (2007) for Switzerland, and Ohlsson et al. (2008) for Denmark and Norway. While some of those papers rely on joining distributional statistics from a multitude of sources over time, we have a single comprehensive source of micro data at our disposal. We can, therefore, allow for considerable degrees of heterogeneity when assessing how households move through the distribution over time.
} 
We start with a descriptive analysis based on the transition patterns that we observe in the data. There are considerable movements into and within the top percents in the wealth distribution. This is not quite consistent with previous results for Sweden presented by Klevmarken (2004). He, however, studies other segments of the wealth distribution than we do. The average duration of being wealthy is about 6 years conditional on ever being wealthy.

Intragenerational wealth mobility has changed considerably over the last four decades. Mobility increased during the 1970s and 1980s. The peak in mobility coincides with the deregulation of the Swedish financial markets during the second half of the 1980s. Wealth mobility has decreased since then. The number of wealthy and the concentration of wealth have increased at the same time.

We provide an in-depth analysis of the likelihood of individual households being wealthy in the estimation part of the paper. ${ }^{3}$ We do not only account for time effects explicitly, but also control for age and other life cycle-related variables. Among those, hump-shaped age patterns are clearly borne out, with peaks around the standard age of retirement, giving rise to broadly support life cycle consumption smoothing motives. Family-size related demographics are typically not among the main drivers of observed patterns. Household-level heterogeneity in total, however, both observed and unobserved, delivers the largest contribution to explaining the observed variation in the sample. The probability of being wealthy is higher when households experience high income uncertainty. This is consistent with precautionary motives for savings and wealth accumulation. The overall effect is small, however.

An important aspect of this paper's use of the data is that we can control for unobserved heterogeneity not only through a random effects approach, but also directly by way of including individual-specific dummy variables. We, therefore, do not need to rely on conditioning out the heterogeneity terms, instead we can estimate them directly at the individual level. This is possible as we have access to such uniquely long individual time-series. Accounting for such detail on individual differences has, to our knowledge, not been done and not been possible before in this context. ${ }^{4}$

The estimated heterogeneity terms are positively correlated with being wealthy. They are also correlated in intuitive ways with a range of observable householdlevel characteristics. We, for example, include a regressor for ever reporting selfemployment income (or profits and losses) which we observe for some part of our sample period. Personal wealth and self-employment are strongly positively correlated. This observation is consistent with returns to entrepreneurial abilities and risk taking but possibly also with liquidity constraints.

The rest of the paper is structured as follows: Section 2 presents our theoretical framework. We present the data source, the data set, and the variables we use in

\footnotetext{
${ }^{3}$ Transition models for becoming wealthy, however, tell much of a similar story.

${ }^{4}$ In a companion paper, Hochguertel and Ohlsson (2011), we study heterogeneous wealth profiles over individual life cycles, but focus on a particular sub-sample.
} 
Section 3. Section 4 reports descriptive results on wealth mobility. The estimation results are reported in Section 5. Section 6 concludes.

\section{Theoretical framework}

The objective of this section is to discuss the implications for wealth accumulation of the choices that the individual makes concerning consumption and savings. ${ }^{5}$ The approach is to start by focusing on the modeling assumptions needed to have individuals making the same choices rather than different choices.

The homogenous case - age effects only. Suppose that there is no uncertainty. Individuals have the same length of life and no bequest motives. They meet the same constant rate of interest. Each household consists of a single individual. Utility is additively separable, the instantaneous utility function does not change over time, and the time preference is constant.

The individual chooses a consumption path $C_{t}, t=1, \ldots, T^{*}$ such as to maximize life time utility $U$,

$$
U=\sum_{t=1}^{T^{*}} \frac{u\left(C_{t}\right)}{(1+\rho)^{t-1}}
$$

subject to an intertemporal budget constraint of the form

$$
\sum_{t=1}^{T^{*}} \frac{C_{t}}{(1+r)^{t-1}}=\sum_{t=1}^{R} \frac{E_{t}}{(1+r)^{t-1}}+W_{0}
$$

Here, $u$ is instantaneous utility with decreasing marginal utility, $t$ is time, $T^{*}$ is the length of life, $\rho$ is the time preference rate, $r$ denotes the rate of interest, $R$ is the retirement age, $E$ is earnings, and $W_{0}$ is the value of initial wealth in the beginning of period 1. The left hand side of equation (2) is lifetime consumption $C^{L}$, the right hand side lifetime resources consisting of lifetime earnings $E^{L}$ and initial wealth. Provided that $R<T^{*}$, there will be retirement saving so that the individual can consume when retired. Consumption will be smoothed over the life cycle.

Let us add the following assumptions: Suppose that the interest rate and the time preference rate are zero, that initial wealth is zero, and that annual earnings are constant during the individual's working life. The individual will choose to consume a fixed share of lifetime earnings every year. This will result in a piecewise linear age-wealth profile with increasing wealth until retirement, a wealth peak at retirement, and then decreasing wealth. Wealth $W$ of individual $i$ will evolve according to

$$
W_{i t}=W_{i t-1}+\left(1-D_{i}^{R}\right)\left(\frac{1}{R_{i}}-\frac{1}{T_{i}^{*}}\right) E_{i}^{L}-D_{i}^{R} \frac{1}{T_{i}^{*}} E_{i}^{L},
$$

\footnotetext{
${ }^{5}$ The discussion is inspired by Davies and Shorrocks (1999) and Dynan et al. (2004).
} 
where $D_{i}^{R}$ is an indicator equal to one when individual $i$ is retired and zero otherwise. The savings rate of a working individual is

$$
s_{i t} \equiv \frac{W_{i t}-W_{i t-1}}{E_{i}^{L}}=\frac{1}{R_{i}}-\frac{1}{T_{i}^{*}} .
$$

Suppose that individuals are identical except for age. During their working life individuals will move up in the wealth distribution both in absolute and relative sense, as retired individuals will move down.

The heterogenous case. It is an old question in the economics literature whether wealthy people save more than people who are not wealthy. Dynan et al. (2004) discuss under which conditions savings rates are the same. Savings rates provide a link between income and wealth. Suppose that individuals have different lifetime earnings while there is no uncertainty and there are no bequest motives. With identical savings rates for a cohort $j$, the wealth of an individual belonging to the cohort will evolve according to

$$
W_{i j t}=W_{i j t-1}+s_{j t} E_{i j}^{L} .
$$

The cohort specific savings rate is $s_{j t}$. Consumption is proportional to lifetime earnings for the individual either if (i) the time preference rate is constant and equals the rate of interest or if (ii) preferences are homothetic. In the first case annual consumption will be the same every year, in the second case annual consumption will grow at the same rate every year. In addition, suppose that preferences, length of life, and rates of interest are the same for all individuals. The ratio of consumption to lifetime earnings at time $t$ is the same for all individuals belonging to cohort $j$. Finally, suppose that the relative differences between individuals in annual earnings are constant over time. The savings rate at time $t$ will then, with these assumptions, be the same for all individuals belonging to cohort $j$. There will, in other words, be no cross section variation at time $t$ for those of the same age. The savings rate might, on the other hand, vary over time (age) for a given cohort. During their working life individuals will move up in the wealth distribution both in absolute and relative sense. Those with higher lifetime earnings will move faster and end up with more wealth at retirement than those with lower lifetime earnings.

Relaxing any of these assumptions and instead introducing, for example, differences in preferences or earnings profiles, rates of interest, length of life, retirement age, or introducing uncertainty, bequest motives, and liquidity constraints will result in less homogeneity across individuals in wealth accumulation.

\section{Data}

Our data are from the Longitudinal INdividual DAta base (LINDA), a data source collected and maintained by Statistics Sweden. ${ }^{6}$ The source data are various ad-

\footnotetext{
${ }^{6}$ Edin and Fredriksson (2000) presents the data base.
} 
ministrative data bases from government agencies that keep records on any (registered) inhabitant in the country. For instance, data from the tax authorities, the social security administration, and from local municipalities. We have spent considerable effort to get at coherent definitions of variables from an array of different variables for different years in the source data.

\subsection{The samples}

The data come in two sub-samples, that we refer to as the P-sample (the panel sample) and the F-sample (the family sample). For the P-sample, the data were randomly drawn in 1994 with a sample size of 300,000 households, comprising almost 700,000 individuals. This sample is available from 1968 to 1999. A household in the data set is a group of people treated as a taxable unit. For the vast majority of cases, this coincides with a residential household or a family.

The F-sample is available to us from 1991 until 2005. Hence, there is an overlap of 1991-1999, where both samples are available. In the F-sample, the sampling unit is a "family", that is, persons living at the same address according to the population register. Since there may be several sub-households within a "family" that are treated as separate taxable units, and since members of the same tax households may live at different addresses, it is possible that the definitions of "households" in the P-sample and of "family" in the F-sample do not coincide. A "family" is, on average, slightly larger than a "household".

We can, however, link both P- and F-samples over time through the identity of the sampled index person. Appendix A provides some more details on the procedure.

The administrative nature of the data implies that there is no panel data attrition as is known from survey data. Theoretically, a person can leave the sample by emigration or death (and only in a few cases where records could not be traced in the source data bases). Persons enter by birth or by, say, marrying into an existing unit.

\subsection{The wealth variable}

The dependent variables we use are derived from annual taxable net wealth at the household level. We will present some main facts about the Swedish wealth tax in this Subsection. Appendix B reports more details.

The wealth tax base was a comprehensive measure of household net wealth (including real assets and financial assets minus debts). Taxable wealth did, however, not include pension wealth in the sense that the value of future public and occupational pensions were not included; neither were savings in tax deferred pension savings accounts. Wealth taxation was affected by tax evasion and tax avoidance. Tax compliance was, however, high for assets for which there was third party reporting. The Tax Agency was by law required to only keep the wealth information 
Figure 1: Shares paying wealth tax and being "millionaires", 1968-2005, percent

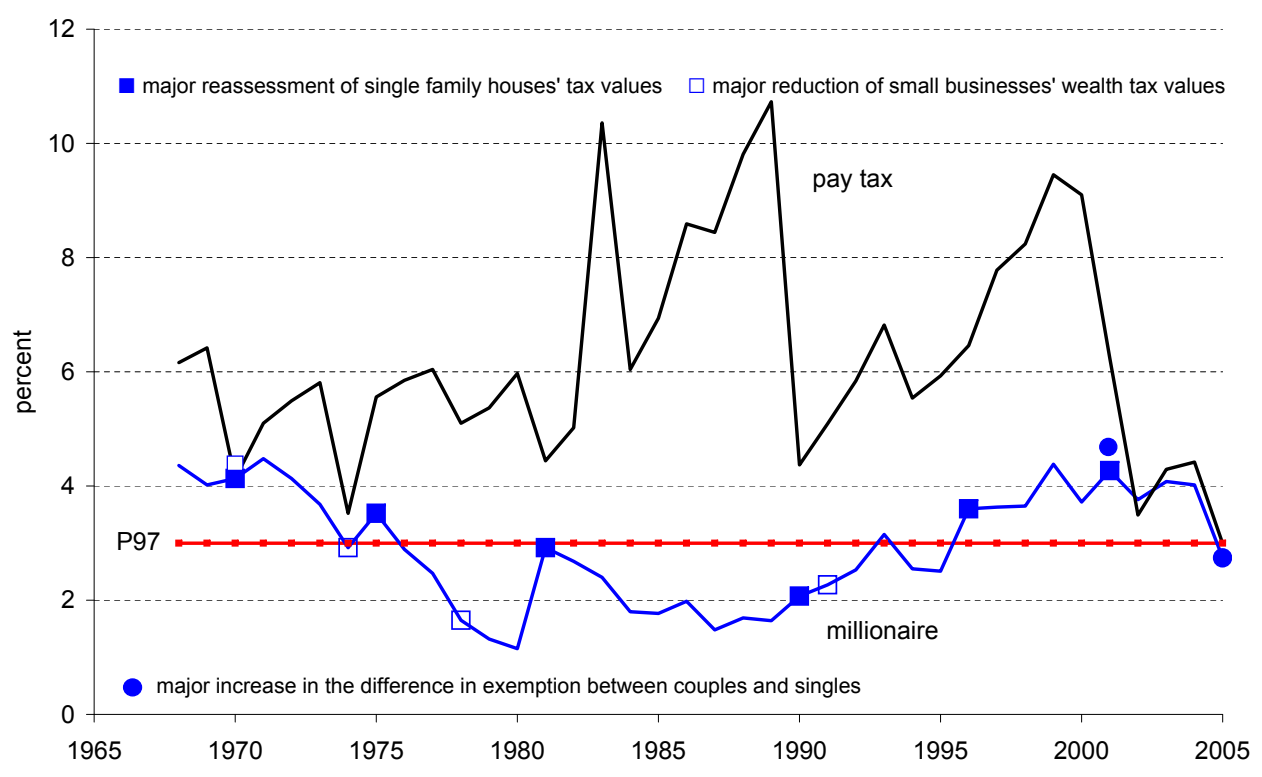

for those having to pay the wealth tax. This severely limits the observability of wealth in the data.

We, therefore, do not use the wealth amounts directly. Instead we use qualitative information on whether the household paid the wealth tax or was wealthy in an absolute or relative sense.

Figure 1 shows the percentage share of wealth tax paying households in Sweden 1968-2005, see the top solid line in the figure. It is clear that we have information for the five top percent for most years, but complete data for the whole period are only available for the top three percent. The design of the system for taxing wealth has varied during the period, for instance concerning tax rates and exemption levels. Many more households paid wealth taxes during the 1980s and the second half of the 1990s. Almost 12 percent of the households paid the wealth tax at least once during the period. More than a third of the households that we can continuously observe 1968-2005 paid wealth taxes some time during the period. ${ }^{7}$

Paying wealth tax or not is one of the possible distinctions between states that can be made for these data. We are, however, here more interested in the percentiles of the wealth distribution. There is only complete information over time for the top three percent of the cross-sectional wealth distribution. We will use the distinction between belonging to the top three percent or not. We can also study the flows in to and out the top three percent (across the 97th percentile, P97) and the flows within the top three percent (across P98 and P99). Almost 6 percent of the households belonged to the top three percent at least once during the period. Slightly more

\footnotetext{
${ }^{7}$ Table B.2 in Appendix B presents data on average wealth amounts 1968-2005 for the different classifications we use for who is wealthy.
} 
than 17 percent of the households that we can continuously observe during 19682005 belonged to the top three percent of the cross sectional wealth distribution for at least one year during the period. These patterns suggest that life-cycle effects have a considerable role.

We can also compute an absolute real measure instead of this relative measure. This will give a related but different distinction. The highest real exemption level, defined as the nominal exemption level in relation to nominal GDP per capita, during the period was the one in 1970 . The real value was $\approx \mathrm{SEK}_{2010} 1.5$ million. This corresponds to EUR 2010160,000 and $\mathrm{USD}_{2010} 210,000$.

We have information on all fortunes above this real wealth threshold during the whole period. We will use the metaphor millionaires to refer to the households above this threshold. Slightly more than 6 percent of the households was a "millionaire" at least once during the period. Almost 18 percent of the households that we can continuously observe 1968-2005 was a "millionaire" some time during the period.

Figure 1 also shows how the share of "millionaires" has evolved during the period. The share of households above the real wealth threshold that we have imposed shows a decreasing trend until 1980. Since then the trend has been reversed, an increasing share of the households is above the real wealth threshold.

There are three types of changes in the wealth tax design that have affected assessed wealth considerably:

a. Major reassessments of single family houses' tax values is the first type of change. House prices increased continuously while these assessments were not made every year. This meant that the assessed values increased considerably when the assessments were made. Political pressure often resulted in politicians responding by increasing the wealth tax exemption levels. There were major reassessments in 1970, 1975, 1981, 1990, 1996, and 2001.

b. Changes in the fraction of wealth in small businesses (working capital) that was tax exempted is the second type of change. All small business wealth was included in the tax base in the beginning of the studied period. Strong pressure groups succeeded in step by step increasing the fraction that was wealth tax exempt. Small business wealth was completely exempt from wealth taxation from 1991. Before this, reductions were made in 1970, 1974, and 1978.

c. The number of household members did not matter for wealth taxation until 2001, only total household wealth mattered. Couples got a higher exemption than singles from 2001. The difference in exemption increased considerably in 2005. Many couples no longer had to pay the wealth tax as their exemption increased, whereas singles with the same wealth still had to pay the tax. Increases in this exemption difference, therefore, decreased the proportion of couples in our sample. 


\subsection{The control variables}

The set of control variables we have at our disposal from LINDA is quite limited, but we do have important demographics for the household index person: The time invariant variables are year of birth, place of birth, gender, and education. ${ }^{8} \mathrm{We}$ also observe the marital status of the household index person (time varying). We know the household size, the number of children and their ages (time varying). ${ }^{9}$ The employment income of the household is also known to us. ${ }^{10}$ The correspondingly long series on incomes also allow us to construct measures of permanent (time constant) and transitory (time varying) income variances. We include these variables as additional regressors to estimate precautionary savings responses to income uncertainty. Appendix A.3 provides the details of these measures that rely on within-household variation of income.

It is unfortunately not possible to identify all individuals who are entrepreneurs and self-employed. There is information on business income for some self-employed from 1991 on. Most of these self-employed run businesses that are not incorporated. It is, however, not possible to throughout the studied period identify owners of incorporated firms who report employment income rather than business income.

We include a number of time-varying variables to correct for specific changes over time: real GDP growth, the change of a stock market index, and the changes in regional house price indices. ${ }^{11}$

Finally, we include some aspects of the design of the wealth tax: the lowest and the highest marginal wealth tax rates, the exemption levels for singles and couples in real value, the changes in the regional tax assessed values of single family houses, and the fraction of working capital in small businesses that was exempt from taxation.

\section{Descriptive results on wealth mobility}

\subsection{Wealth flows and wealth durations}

Table 1 reports transitions during the period 1968-2005. The left hand panel shows flows into and out of the top three percent of the distribution. The right hand panel reports transitions crossing the real wealth threshold from below (inflow) and

\footnotetext{
${ }^{8}$ Education, measured as the highest level obtained, is not strictly time-constant for everyone, but we treat it as such.

${ }^{9}$ We control in regressions for number and age composition of children to capture the fact that larger households may be wealthier because they have more members. This is an alternative, and possibly less controversial approach, to equalize wealth across different demographic household types.

${ }^{10}$ Employment income includes salaries and, since 1974, social insurance system benefits (such as sickness benefits and parental benefits), and unemployment benefits. Approved costs for commuting to work are subtracted. Employment income also includes public pensions and occupational pensions.

${ }^{11}$ Note that regional house price indices vary over both time and regions.
} 
transitions in the reverse direction (outflow). From now on, we study transitions between two discrete states: being in the top three percent (state 1), and not being in the top three percent (state 0). Alternatively, we consider being or not being a "millionaire".

There is some variation over time in the inflow rates to the top three percent. This might be attributable to macroeconomic shocks and asset price changes, for instance. Most years the inflow rate is around 0.5 percent while outflow rates are in the range 15-20 percent. Obviously, inflow and outflow rates are by definition highly correlated in this case as the share is fixed to three percent. The years in which the major changes in the wealth tax design occurred are in bold. Flows are, in general, higher than otherwise these years.

Mobility is closely related to duration, high mobility implies short duration. The average outflow rate from the top three percent of 16.64 suggests an average duration in the top three percent of 6.01 years. Average duration is often referred to as mean exit time (MET) in the mobility literature. The average outflow and inflow rates together suggest a top three equilibrium share of 3.54 percent. These flow rates, therefore, are not at a long run equilibrium.

Turning to the second distinction, there is more variation in the inflow into being a "millionaire" than the inflow to the top three percent. This inflow rate is in the range $0.2-1.5$ percent while the outflow rate is in the range 10-30 percent.

The average outflow rate from being a "millionaire" of 18.05 suggests an average duration as "millionaire" of 5.54 years. The average outflow and inflow rates together imply a long run "millionaire" share of 3.22 percent. The actual average "millionaire" share is about the same. Flows are also in this case, in general, higher than otherwise these years.

Starting from a life-cycle model perspective, we would expect it to be more likely to observe people above the cutoffs when they are in their 50s and 60s and until they retire. Transitions into the top three percent or into becoming a "millionaire" would then be more likely when people accumulate wealth, while transitions in the other direction would be more likely when people have retired.

While Table 1 is illustrative on average transition probabilities it masks differences in wealth transitions. Our data give long uninterrupted accounts of wealth status. There are 673,912 households for which we at least have non-missing observations for at least two adjacent years. Of these, 93.7 percent were never in the top three percent, while 5.8 percent were in the top three percent some of the years observed but not all. A small fraction of the households, 0.6 percent, were in the top three percent in every year.

Figure 2 shows the frequency distribution of the time spells when belonging to the top three percent. Most spells are short, half of the spells are shorter than 3 years. The number of longer top three percent spells is very low.

We can also calculate the total number of years in the top three percent. Households always in the top three percent have a fraction of 13.45 percent of the total number of top three years. The rest of the top three years, 86.55 percent, are for households sometimes in the top three percent. We know that a household in this 
Table 1: Transitions over time, 1968-2005

\begin{tabular}{|c|c|c|c|c|}
\hline \multicolumn{3}{|c|}{ the top three percent } & \multicolumn{2}{|c|}{ "millionaire" } \\
\hline between & inflow, percent & outflow, percent & inflow, percent & outflow, percent \\
\hline $\begin{array}{l}\text { annual } \\
1968-2005\end{array}$ & 0.61 & 16.64 & 0.60 & 18.05 \\
\hline $1968-1969$ & 0.49 & 11.09 & 0.51 & 14.65 \\
\hline 1969-1970 & $\mathbf{0 . 8 3}^{a}$ & $13.89^{b}$ & $1.22^{a}$ & $12.82^{b}$ \\
\hline 1970-1971 & 0.30 & 16.72 & 0.56 & 12.19 \\
\hline 1971-1972 & 0.37 & 9.06 & 0.38 & 13.63 \\
\hline $1972-1973$ & 0.40 & 9.92 & 0.32 & 15.67 \\
\hline 1973-1974 & 0.49 & $12.80^{b}$ & 0.23 & $24.30^{b}$ \\
\hline 1974-1975 & $0.70^{a}$ & 18.89 & $1.09^{a}$ & 10.93 \\
\hline $1975-1976$ & 0.46 & 11.45 & 0.25 & 22.43 \\
\hline $1976-1977$ & 0.48 & 12.44 & 0.24 & 20.10 \\
\hline 1977-1978 & 0.87 & $25.25^{b}$ & 0.22 & $40.21^{b}$ \\
\hline 1978-1979 & 0.58 & 15.60 & 0.16 & 27.18 \\
\hline 1979-1980 & 0.59 & 15.79 & 0.18 & 23.80 \\
\hline 1980-1981 & $1.06^{a}$ & 31.16 & $1.97^{a}$ & 6.72 \\
\hline 1981-1982 & 0.54 & 14.58 & 0.40 & 19.19 \\
\hline 1982-1983 & 0.55 & 15.27 & 0.36 & 21.35 \\
\hline 1983-1984 & 0.53 & 13.44 & 0.17 & 29.29 \\
\hline 1984-1985 & 0.53 & 13.33 & 0.32 & 15.15 \\
\hline 1985-1986 & 0.61 & 16.54 & 0.51 & 12.93 \\
\hline 1986-1987 & 0.66 & 18.39 & 0.20 & 33.77 \\
\hline 1987-1988 & 0.66 & 18.21 & 0.50 & 15.70 \\
\hline 1988-1989 & 0.60 & 16.28 & 0.34 & 19.10 \\
\hline 1989-1990 & $0.99^{a}$ & 29.03 & $\mathbf{0 . 8 3}^{a}$ & 20.23 \\
\hline 1990-1991 & 0.58 & $25.54^{b}$ & 0.51 & $22.06^{b}$ \\
\hline 1991-1992 & 0.66 & 18.34 & 0.71 & 15.32 \\
\hline 1992-1993 & 0.57 & 15.21 & 0.96 & 8.29 \\
\hline 1993-1994 & 0.78 & 20.74 & 0.43 & 28.85 \\
\hline 1994-1995 & 0.51 & 14.04 & 0.42 & 15.27 \\
\hline 1995-1996 & $0.64^{a}$ & 16.80 & $1.45^{a}$ & 7.15 \\
\hline 1996-1997 & 0.55 & 14.87 & 0.70 & 15.14 \\
\hline 1997-1998 & 0.42 & 11.47 & 0.53 & 11.05 \\
\hline 1998-1999 & 0.57 & 15.33 & 1.19 & 7.76 \\
\hline 1999-2000 & 0.47 & 11.87 & 0.35 & 19.69 \\
\hline 2000-2001 & $\mathbf{0 . 6 3}^{a}$ & $18.40^{c}$ & $1.14^{a}$ & $11.94^{c}$ \\
\hline 2001-2002 & 0.64 & 17.97 & 0.55 & 22.16 \\
\hline $2002-2003$ & 0.50 & 13.99 & 0.86 & 10.85 \\
\hline 2003-2004 & 0.42 & 11.10 & 0.52 & 11.34 \\
\hline 2004-2005 & 0.83 & $\mathbf{2 4 . 7 0 ^ { c }}$ & 0.31 & $37.99^{c}$ \\
\hline
\end{tabular}

Notes: ${ }^{a}$ major reassessment of single family houses' tax values,

${ }^{b}$ major reduction of small businesses' wealth tax values,

${ }^{c}$ major increase in the difference in exemption between couples and singles. 
Figure 2: Frequency distribution of top three percent spells, percent

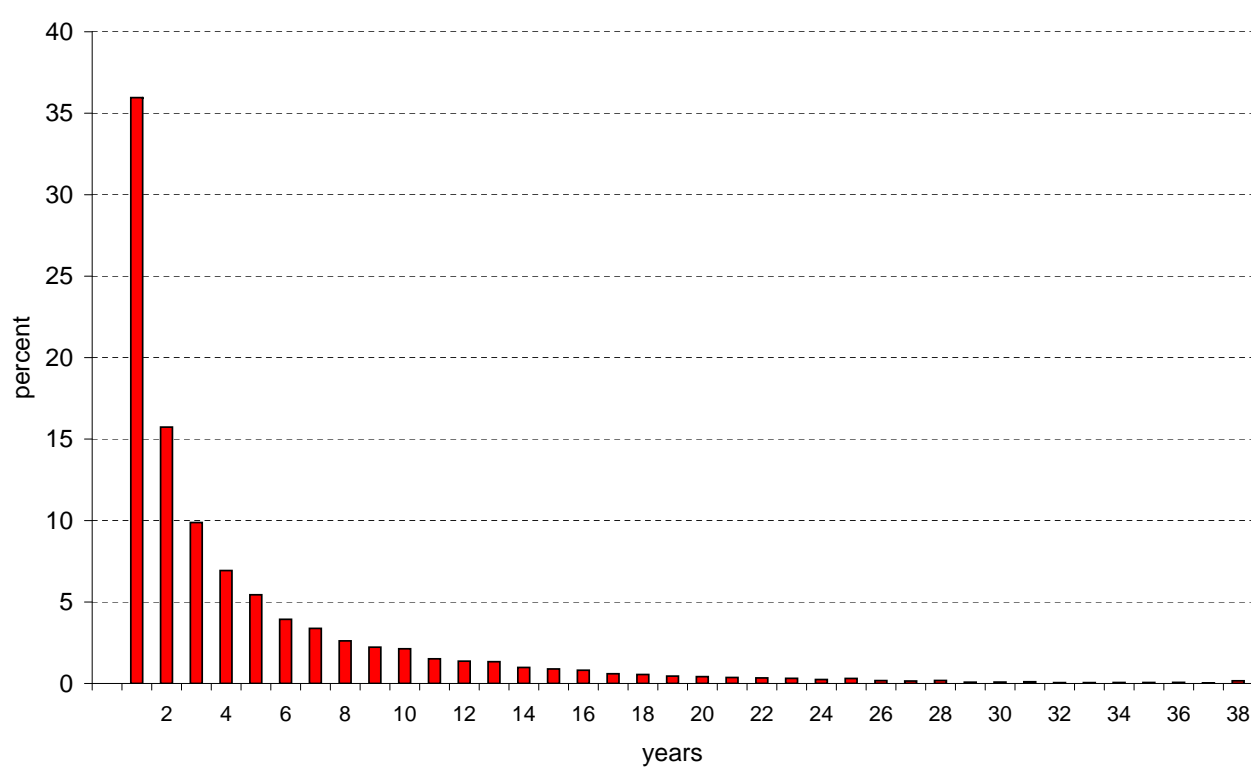

Figure 3: Frequency distribution of top three percent years, percent

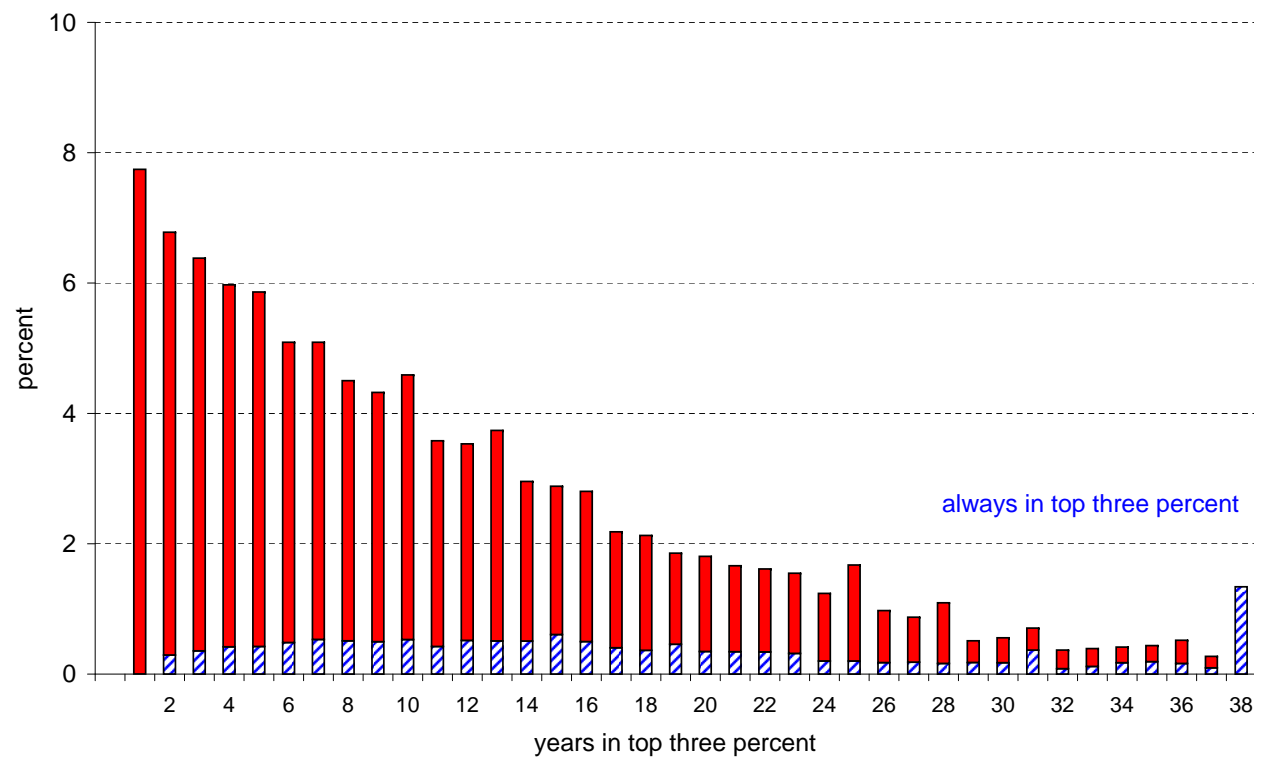


group at least once enters or leaves the top three percent.

Figure 3 reports the frequency distribution of top three percent years for different top three percent spell lengths. Almost half the top three percent years are for households with top three percent spell lengths shorter than eight years. It is also clear from the figure that the contributions of always top three percent households are very small. The exception is for the top three percent spell length of 38 years where all households by definition always are wealthy.

\subsection{Wealth mobility and wealth stability}

An often used summary measure in the previous literature on wealth mobility is the Shorrocks measure of mobility, see Shorrocks (1978b). ${ }^{12}$ It is defined as

$$
S=\frac{N-\operatorname{tr}(P)}{N-1}
$$

where $N$ is the number of groups and $\operatorname{tr}(P)$ is the trace of the $N \times N$ transition matrix $P$. The range of $S$ is $[0, N /(N-1)]$. A higher $S$ indicates a higher degree of mobility.

In our case, we select to study four groups, each of the three top percents and those below P97 taken together. Using the average transitions rates of our data, the Shorrocks' measure is 0.386 . This cannot, however, be compared to previous measures of wealth mobility in Sweden as we here only measure mobility for the top three percents. The strength of our data is many observations for each household. We can, therefore, calculate a time series for annual wealth mobility for almost 40 years using the Shorrocks' measure.

Figure 4 shows how wealth mobility has evolved during the studied period. The annual Shorrocks' measures vary considerably. The huge spikes in the Shorrocks' measures coincide with the major changes in the wealth tax design, compare Table 1. Household differences in portfolio composition and marital status might change the assessed household wealth ranking when such major changes occur. It is, however, possible that there are no corresponding changes in the true underlying household wealth ranking.

We have estimated a descriptive regression controlling for the major changes in the wealth tax design. ${ }^{13}$ We also include trend polynomials as regressors. The trend polynomials' estimated coefficients are statistically significant at the 1 percent level. The estimated trend line in the figure suggests that wealth mobility increased during the 1970s and 1980s. The peak in mobility coincides with the deregulation of the Swedish financial markets during the second half of the 1980s. Wealth mobility has decreased since then. Roine and Waldenström (2009) show that the concentration of wealth in Sweden also started to increase 1985.

Wealth stability can be measured as the share of households in the top three percent, respectively, that have stayed in between the percentiles where they were

\footnotetext{
${ }^{12}$ Some refer to the measure as Shorrocks' MET as it is a function of mean exit time from a group.

${ }^{13}$ Table A.1, column 1, in Appendix A reports the results.
} 
Figure 4: Wealth mobility, 1969-2005, Shorrocks' measure

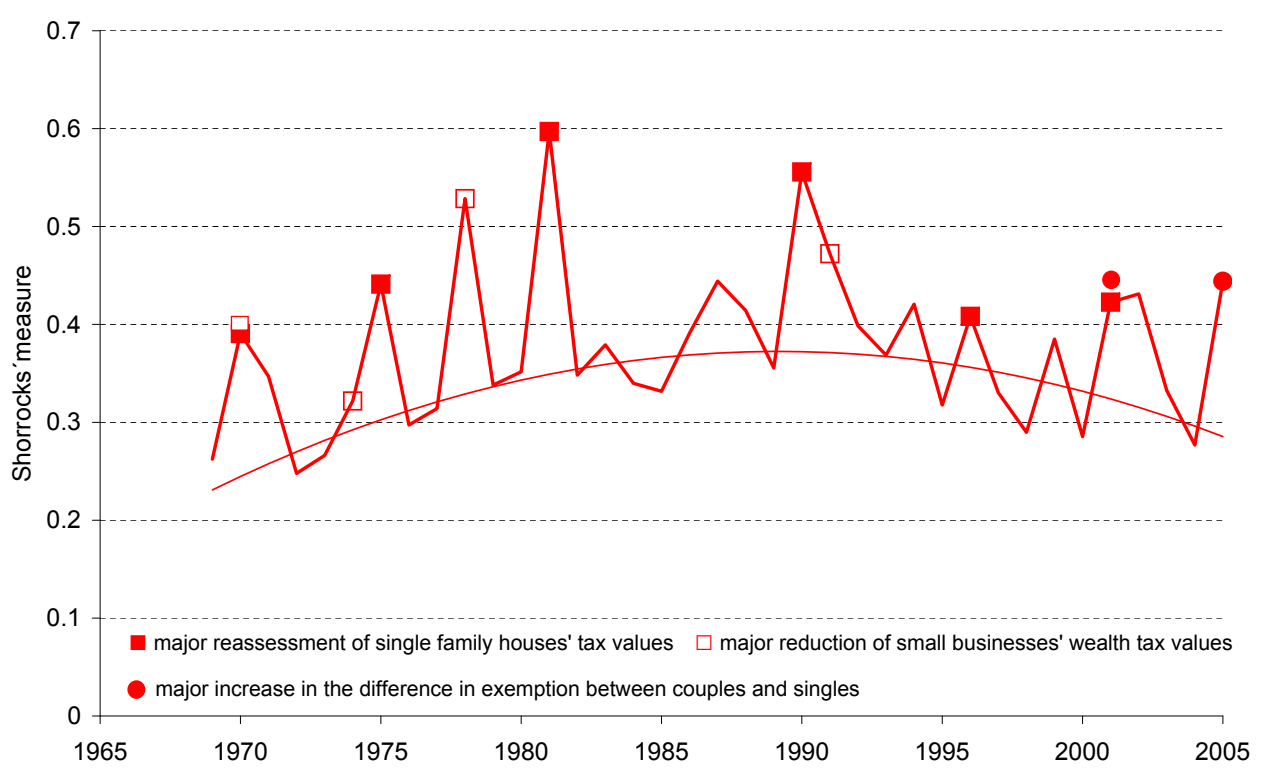

Figure 5: Wealth stability, 1969-2005, adjusted series, percent

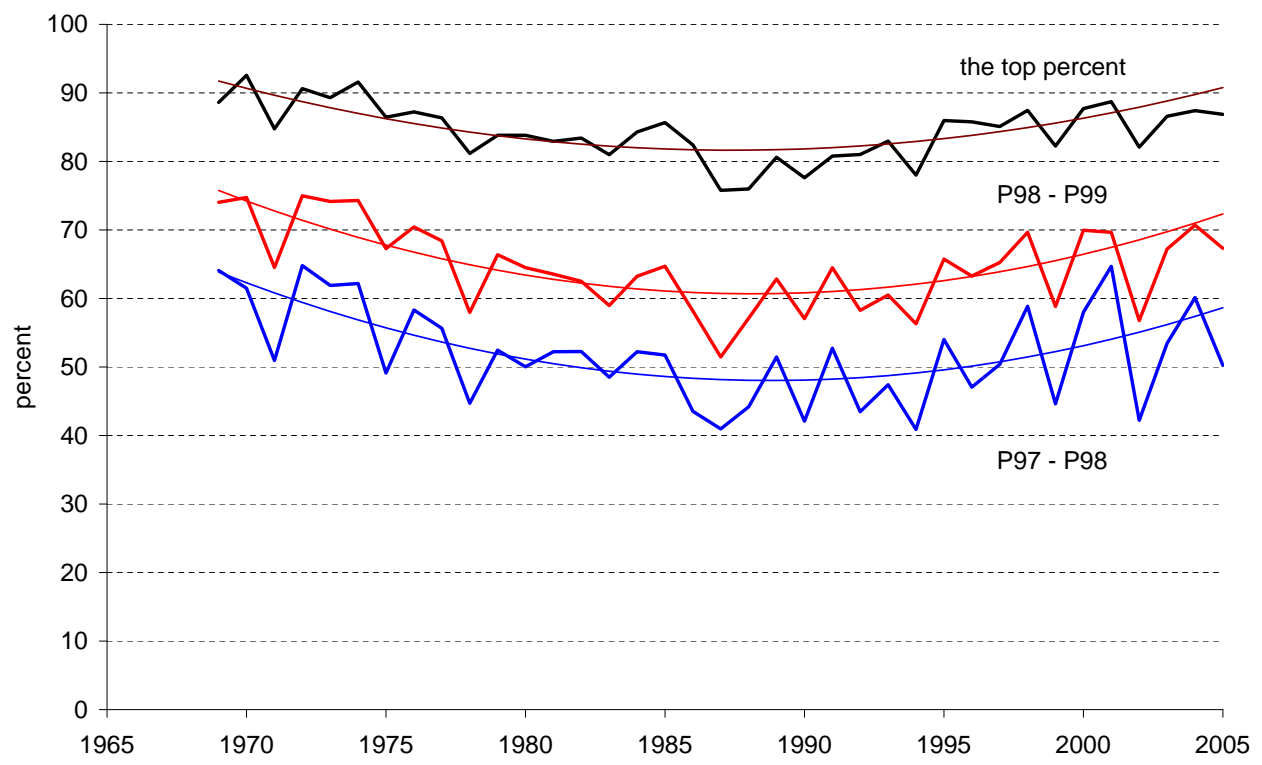


in the previous year. We have estimated descriptive regressions with the three wealth stability measure as dependent variables. We include trend polynomials as regressors and control for the three major changes in the wealth tax design. ${ }^{14}$ Figure 5 shows the wealth stability series adjusted for the estimated effects of the major wealth tax changes.

About 80-90 percent of the households in the top percent remained there the following year. The corresponding number for the next percent is lower. About 60-70 percent of the households between P98 and P99 remained there the following year. Stability is even lower if we turn to the next percent. The share remaining is 50-60 percent for the households between P97 and P98.

The trend polynomials' estimated coefficients are statistically significant at the 1 percent level. The estimated trend lines confirm the findings in Figure 4. Wealth stability decreased during the 1970s and 1980s. From the end of the 1980s wealth stability has increased.

It is also clear from Figure 5 that deviations from the trend line are smaller for the top percent than for households between P98 and P99. These deviations are, in turn, smaller than the deviations for households between P97 and P98. ${ }^{15}$

These descriptives tell a story about the movements in the top percents of the Swedish wealth distribution during the period 1968-2005. But we have far from used all the possibilities that our panel data offer. This will be the objective of the following section.

\section{Estimation results}

This section reports estimations of probability models for being a "millionaire" and belonging to the top three percent. ${ }^{16}$ We start by presenting our approach to estimation in Subsection 5.1. The estimation results when we include all households in the samples are in Subsection 5.2. It is, however, not clear-cut how to separate age effects from cohort effects. We, therefore, also report estimation results when the sample only includes households with an index person born 1940-1950.

We then condition the samples to households that ever have been "millionaires" or in the top three percent. The estimation results for all households in these categories are in Subsection 5.3. We, finally, restrict the conditional samples to only include households with an index person born 1940-1950. The estimation results are in Subsection 5.4.

\footnotetext{
${ }^{14}$ Table A.1, columns 2-4, in Appendix A reports the results.

${ }^{15}$ See RMSE in Table A.1, columns 2-4, in Appendix A.

${ }^{16}$ We have also estimated transition models that condition the sample on "not being wealthy" (either way) in the previous year. Given the sample distributions of the dependent variables, the resulting models yield estimates (available on request from the authors) that convey a largely similar story as those displayed here.
} 


\subsection{Estimation approach}

We choose to include time-varying variables directly instead of including time indicators. Time-varying variables can be interpreted to measure the specific impact of certain macroeconomic events and tax changes.

We include age as a third-degree polynomial and we control for cohort effects. We do this by way of year of birth dummies (random effects approach), or by way of individual fixed effects. We have alternatively considered the approach advocated by Deaton and Paxson (1994). In that paper a full set of age dummies is included along with a full set of time dummies. The latter are restricted to sum to zero and to be orthogonal to a time trend. This alternative normalization will pull up the time patterns estimated in the data, as without the restriction we would find a decreasing trend over time. Age effects are shifted downwards, accordingly, but much in a parallel fashion. Importantly, none of the included demographics coefficients is affected.

We choose to lag some of the control variables by one year. The variables are household employment income, marginal wealth tax rates, and the real wealth tax exemption level. ${ }^{17}$

The estimated models are of four types: The initial sample includes all households with at least two adjacent observations. The first set of estimations is random effects probit models for belonging to the top three percent and being a "millionaire". We condition on time averages of regressors as additional covariates. 18 Mundlak (1978) has shown the equivalence of random and fixed effects linear models when this conditioning is done in random effects models. Our application to nonlinear models is heuristic. Actual fixed effects approaches are consistent as the unobserved fixed effects can be freely correlated with the included time-varying regressors.

The models in the first set are important as they let us estimate the probability that someone is wealthy. The sample includes everyone and is not selected in any way. We draw a 10 percent random sub-sample since the data set is too big to handle with our computer.

The second set of estimations uses a sample only including households with an index person born 1940-1950. We estimate random effects probit models for belonging to the top three percent and being a "millionaire" also for this sample.

We then proceed and condition the samples to households that have been "millionaires" or in the top three percent at least once. This makes it possible for us to estimate fixed effects models. Fixed effects models are more flexible as all timeconstant unobservables are essentially captured by the fixed effect and arbitrary correlation with the included observables is possible. Fixed effects may also suf-

\footnotetext{
${ }^{17}$ Note that we include annual system parameters and not (endogenous) actual tax rates paid by individual households. Yet, there may be aggregate feedback effects from including contemporaneous values. Lagged household income is meant to be predetermined.

${ }^{18}$ The only exception is that we do not include the time-average of the transitory variance of income uncertainty, which is highly correlated with the permanent variance.
} 
fer less from differential mortality bias (Shorrocks, 1975; Attanasio and Hoynes, 2000) as they condition on the identity of the individual household. This is an important selection issue.

If we want to calculate marginal effects, we need to have an estimate of the fixed effect at the individual level. We, therefore, need to include dummy variables. To have this consistent, however, we need to condition on a long panel (30 and more time observations). We follow Greene (2004) and program a routine that allows inclusion of literally thousands of dummy variables in estimation without having to handle (compute, store, invert) associated large sparse matrices. This way we can recover the fixed effects as estimated parameters and study the correlation with observables. This cannot be done if we use random effects probit or fixed effects logit.

The third set of estimations is fixed effects probit models and random effects probit models with Mundlak-corrections for belonging to the top three percent and being a "millionaire". The samples used include all households with 30 or more observations that have ever belonged to the top three percent or been "millionaire". ${ }^{19}$ We report marginal effects and predicted probabilities. The fourth set of estimations repeats all this restricting the samples to households with an index person born 1940-1950.

Using the conditional samples to estimate a fixed effects probit models has a remaining double selection issue: (i) it conditions on those that become wealthy (as a conditional logit also would do), (ii) among those, it selects those that stay long in the sample. There is no self-selection as we use register data, but there is selection on year of birth as old and young cohorts are removed by the requirement of 30 or more observations.

\subsection{Unconditional models}

Table 2 reports the results from estimating random effects probit models for being a "millionaire" and belonging to the top three percent. We report the average partial effects (marginal effects) and the statistical significance of the underlying coefficient. Average partial effects are calculated as follows: per individual household, we add a draw from the estimated random effects distribution to the linear prediction, and then calculate an individual probability; we then average the probability across many draws. The average partial effect is calculated as the derivative (or difference in case of a discrete regressor) of that probability.

The models are estimated using two samples; all households and households with an index person born 1940-1950.

\footnotetext{
${ }^{19}$ Appendix $\mathrm{C}$ reports estimations of conditional logit models and fixed effects dummy variables logit models. The coefficient estimates are displayed in Table C.1 together with the coefficient estimates of corresponding fixed effects dummy variables probit models. The conditional logit models do not allow calculating predicted probabilities nor marginal effects and can only identify the coefficients from a sample that ever becomes wealthy. The objective is to assess possible selectivity, in particular the restriction that only households with 30 or more observations are included.
} 
Table 2: Random effects probit models, unconditional samples, average partial effects

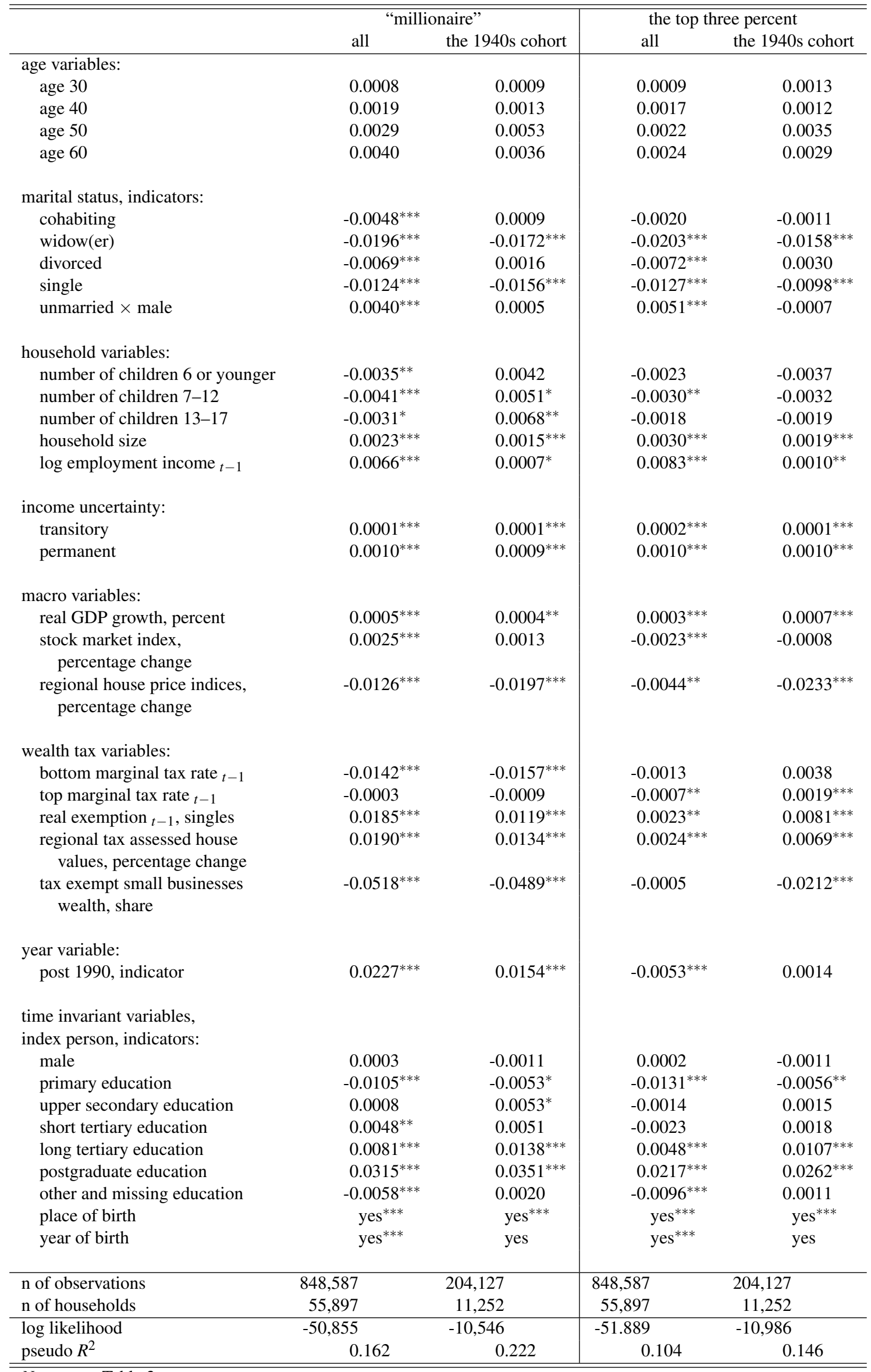

Notes: see Table 3. 
Table 3: Notes to Tables

\begin{tabular}{|c|c|}
\hline Table No. & Notes \\
\hline $2,4,5,6,7$ & $\begin{array}{l}*, * * \text {, and } * * * \text { denote statistical significance at the } 10,5 \text {, and } 1 \text { percent level, } \\
\text { respectively, of the underlying coefficient. }\end{array}$ \\
\hline & These, and associated standard errors available from the authors on request. \\
\hline $2,4,5,6,7$ & $\begin{array}{l}\text { Reference categories for dummy variable groups: } \\
\text { married and lower secondary education }\end{array}$ \\
\hline $2,4,6$ & $\begin{array}{l}\text { Random effects models also include as regressors } \\
\text { time-averages of time-varying variables. }\end{array}$ \\
\hline $2,4,6$ & $\begin{array}{l}\text { Average partial effects for an extra year of age are based on a third degree } \\
\text { polynomial in age and an interaction of age and the number of non-adult children. } \\
\text { Effects are displayed at ages } 30,40,50 \text {, and } 60 \text {. } \\
\text { The age variables are jointly statistically significant according } \\
\text { to } \chi^{2} \text {-tests that in all cases yield a } p \text {-value of } 0.000 \text {. }\end{array}$ \\
\hline
\end{tabular}

Average partial effects for an extra year of age are based on a third degree polynomial in age and an interaction of age and the number of non-adult children. We do not report the statistical significance of the underlying coefficients in the tables for the age variables. The age variables are jointly statistically significant in all reported estimations according to $\chi^{2}$-tests that in all cases yield a $p$-value of 0.000 .

Being married increases the probability of being a "millionaire" and belonging to the top three percent. Men living on their own are more likely to be wealthy than women living on their own in the full sample. Household size is also associated with increased probabilities of being wealthy. The age distribution within the household is not so important in the sample of the 1940s cohort. This is, however, more the case for the other sample. Household employment income the previous year also increases the probabilities.

Our estimates of the income uncertainty variables suggest that there are precautionary motives for wealth accumulation. All the estimated coefficients for the income uncertainty variables are positive and statistically significant regardless of sample or wealth definition. The average partial effects of permanent income uncertainty are considerably larger than those of transitory income uncertainty. This conforms with intuition (also compare Carroll and Samwick, 1997). The overall effects are small, however. This suggests that precautionary accumulation does not contribute to a large extent to becoming wealthy in our sense. Precautionary accumulation may instead be confined to and be more important for those in the mid deciles of the wealth distribution.

Looking at the $\chi^{2}$ values of joint significance tests, the macro variables are more important for being a "millionaire" than belonging to the top three percent. This suggest that these variables tend to affect absolute wealth but not relative wealth.

A surprising result is the estimated negative impact of (regional) house prices on the probability of being a "millionaire". The estimated house price effect might, 
however, be affected by the inclusion of (regional) tax assessed house values. The latter variable is associated with the expected increased probability of being wealthy. The other wealth tax variables also have expected estimated effects in most cases.

The more education for the index person, the higher the wealth probability is. The place of birth indicators are jointly statistically significant, a $\chi^{2}$-test yields a $p$ value of 0.000 . Being born in the Stockholm area increases the wealth probability. The year of birth is also (jointly) statistically significant for the sample with all households.

The average partial age effects in the table are all positive. The largest effects are for those aged 60 in the sample including all households. For those in the 1940s cohort the largest estimated partial age effects is for those aged 50. This suggests that there are life-cycle motives for wealth accumulation.

We have also calculated age-wealth probability profiles. This has been done in the following way. The probability of being wealthy for each household in each year has been predicted using the estimated coefficients, actual characteristics, and draws from the estimated random effects distribution. This gives an age-wealth probability for each household in each year. We finally calculate the average wealth probability for each age.

Figure 6 and Figure 7 show the resulting age-wealth probability profiles for the two samples. Starting with the sample with all households it is clear that the unconditional age-wealth probability profiles are increasing until the index person is in the mid 60s. The maximum unconditional probability for being a "millionaire" is for the age of 61 . The corresponding age for maximum unconditional probability of belonging to the top three percent is also 61 . The maximum unconditional wealth probability age for the 1940s cohort is 63 for both wealth definitions. ${ }^{20}$

The age-wealth probability pattern is consistent with the life-cycle model in the sense that wealth first increases and then decreases. The peaks in the probability of being wealthy occur at ages when retiring for most. This is consistent with lifecycle motives for wealth accumulation. The wealth probability is positive even for the very old. It is an open question why this is the case. It might be because of precautionary motives or bequests motives.

\subsection{Conditional models: all households}

The samples used in this Subsection rely on estimating fixed effects as constants. We want to be able to calculate individual probabilities and marginal effects of being wealthy. While capturing all kinds of sources of household specific unobserved heterogeneity, these constants are positively correlated with the probability of being wealthy.

\footnotetext{
${ }^{20}$ There are few observations for the 1940s cohort when they are in their mid 60s. The only observations we have of age 64 are in 2004 for those born in 1940. The only observations we have of age 63 are in 2003 for those born in 1940 and in 2004 for those born in 1941. This might explain why the probabilities do not increase continuously.
} 
Figure 6: Unconditional age-wealth probability profiles, all

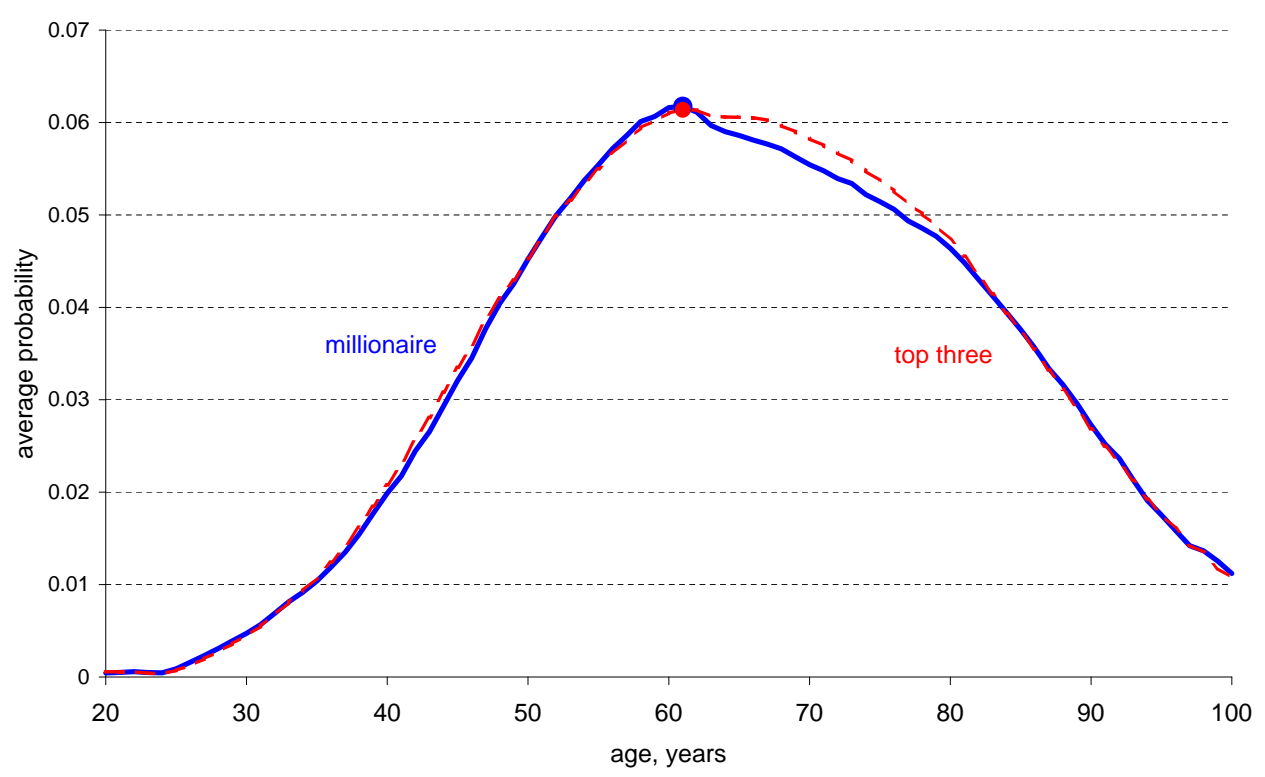

Figure 7: Unconditional age-wealth probability profiles, the 1940s cohort

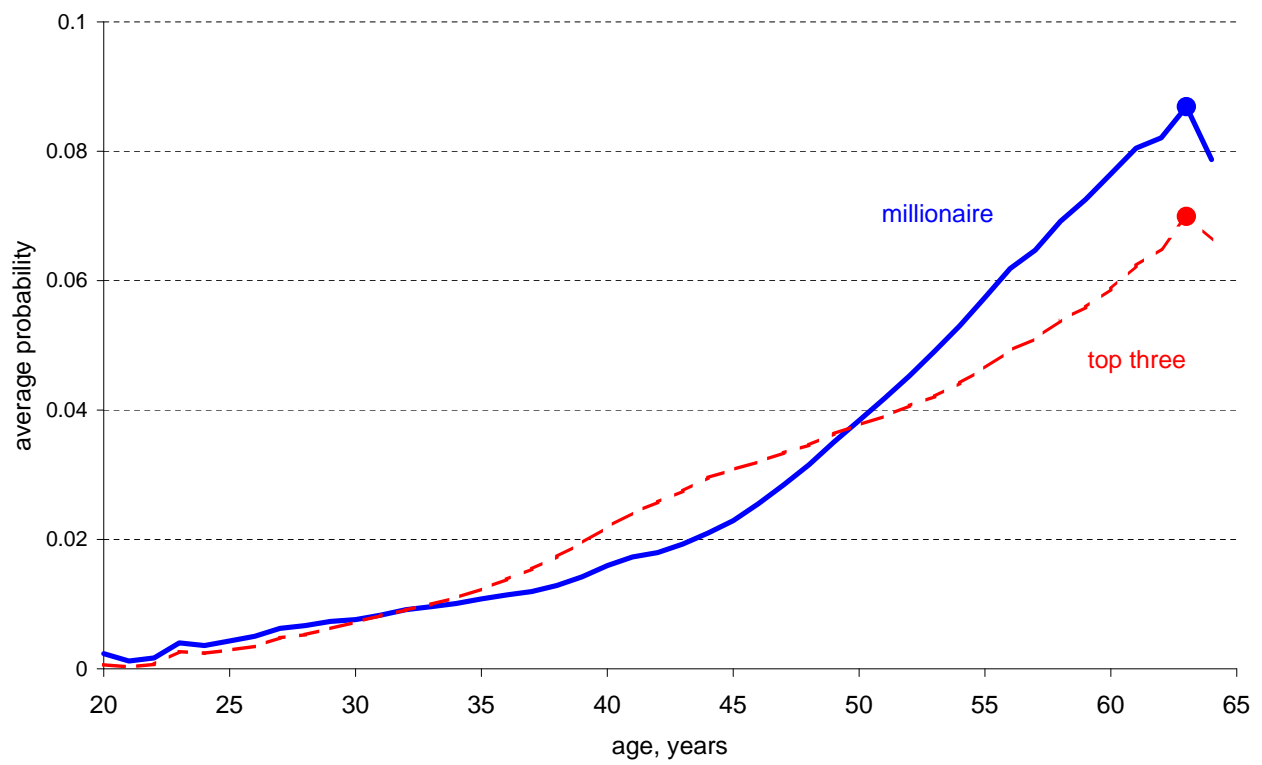


Imposing the sample restriction that each household has to be in the data for at least 30 years, will tend to select households whose index person is born in particular years, such that its data fall into our observation window 1968-2005. Younger households, born for instance in the 1980's, or older households that died before the 1990's, are unlikely to be included. While the fixed effects approach captures the impact of cohort specific effects and allows them to be freely correlated with all other included regressors, drawing such a sample will tend to exclude young and old cohorts.

Appendix $\mathrm{C}$ further compares estimates obtained from varying the restriction on the number of periods $T_{i}$ per household. This appendix shows that the variation in sample length is not very important for the estimated coefficients and that there are only very small differences in coefficient estimates between a conditional logit model, that we assume to be consistent, and the fixed effects (dummy variables) estimates. These findings are reassuring, and underline that the marginal effects displayed in our main tables are not driven by sample restrictions.

Columns 1 and 2 in Table 4 report the average partial effects (marginal effects) from a fixed effects probit and a random effects probit for being a "millionaire" conditional on having been a "millionaire" some time during the studied period. The remaining columns report the average partial effects for belonging to the top three percent conditional on having been in the top three percent some time during the studied period. It is clear from the table that the random effects coefficient estimates differ very little from the fixed effects coefficient estimates.

Being two adults in the household, rather than one, and being married increases the probabilities of being a "millionaire" and belonging to the top three percent. The estimated marital status indicators support this. So does the estimated effect of household size while the number of minor children decreases the probability. Men living on their own are more likely to be wealthy than women living on their own. Household employment income also has an estimated positive impact.

The conditional models also suggest that there are (limited) precautionary motives for wealth accumulation. The estimated coefficients for the income uncertainty variables are positive and statistically significant regardless of sample or wealth definition. The relative weights of permanent and transitory income uncertainty, however, differ here compared to the unconditional models.

The estimated effects of economic growth and changes in the stock market index are expected. These variables are more important for being a "millionaire" than belonging to the top three percent. This suggest that economic growth and changes in the stock market index tend to affect absolute wealth more than relative wealth. The wealth tax variables also have expected estimated effects.

The random effects estimation results in the second column reveal households with male index persons are less likely to be "millionaires". Moreover, only one of the education indicators produce statistically significant result. A $\chi^{2}$-test of all education variables taken together, however, produces a $p$-value of 0.000 . 
Table 4: Probit models, conditional samples, average partial effects

\begin{tabular}{|c|c|c|c|c|}
\hline & \multicolumn{2}{|c|}{ "millionaire" } & \multicolumn{2}{|c|}{ the top three percent } \\
\hline & fixed effects & random effects & fixed effects & random effects \\
\hline \multicolumn{5}{|l|}{ age variables: } \\
\hline age 30 & 0.0016 & 0.0010 & 0.0031 & 0.0031 \\
\hline age 40 & 0.0092 & 0.0093 & 0.0112 & 0.0120 \\
\hline age 50 & 0.0191 & 0.0200 & 0.0175 & 0.0190 \\
\hline age 60 & 0.0196 & 0.0201 & 0.0142 & 0.0148 \\
\hline \multicolumn{5}{|l|}{ marital status, indicators: } \\
\hline cohabiting & $-0.1087^{* * *}$ & $-0.1100^{* * *}$ & $-0.1219^{* * *}$ & $-0.1261^{* * *}$ \\
\hline widow(er) & $-0.1777^{* * *}$ & $-0.2054^{* * *}$ & $-0.1889^{* * *}$ & $-0.2190^{* * *}$ \\
\hline divorced & $-0.1369^{* * *}$ & $-0.1300^{* * *}$ & $-0.1469^{* * *}$ & $-0.1401^{* * *}$ \\
\hline single & $-0.1678^{* * *}$ & $-0.1580^{* * *}$ & $-0.1778^{* * *}$ & $-0.1661^{* * *}$ \\
\hline unmarried $\times$ male & $0.0793^{* * *}$ & $0.0803^{* * *}$ & $0.0956^{* * *}$ & $0.0974^{* * *}$ \\
\hline \multicolumn{5}{|l|}{ household variables: } \\
\hline number of children 6 or younger & $-0.0236^{* * *}$ & $-0.0239^{* * *}$ & -0.0104 & -0.0109 \\
\hline number of children $7-12$ & $-0.0352^{* * *}$ & $-0.0357^{* * *}$ & $-0.0242^{* * *}$ & $-0.0255^{* * *}$ \\
\hline number of children $13-17$ & $-0.0384^{* * *}$ & $-0.0388^{* * *}$ & $-0.0263^{* * *}$ & $-0.0276^{* * *}$ \\
\hline household size & $0.0160^{* * *}$ & $0.0158^{* * *}$ & $0.0226^{* * *}$ & $0.0230^{* * *}$ \\
\hline log employment income $t_{t-1}$ & $0.0413^{* * *}$ & $0.0423^{* * *}$ & $0.0658^{* * *}$ & $0.0694^{* * *}$ \\
\hline \multicolumn{5}{|l|}{ income uncertainty: } \\
\hline transitory & $0.0017^{* * *}$ & $0.0018^{* * *}$ & $0.0020^{* * *}$ & $0.0021^{* * *}$ \\
\hline permanent & & $0.0022^{* * *}$ & & $0.0017^{* * *}$ \\
\hline \multicolumn{5}{|l|}{ macro variables: } \\
\hline real GDP growth, percent & $0.0048^{* * *}$ & $0.0050^{* * *}$ & $0.0043^{* * *}$ & $0.0045^{* * *}$ \\
\hline $\begin{array}{l}\text { stock market index, } \\
\text { percentage change }\end{array}$ & $0.0494^{* * *}$ & $0.0512^{* * *}$ & $0.0080^{* * *}$ & $0.0083^{* * *}$ \\
\hline $\begin{array}{l}\text { regional house price indices, } \\
\text { percentage change }\end{array}$ & $-0.0616^{* * *}$ & $-0.0644^{* * *}$ & -0.0102 & -0.0116 \\
\hline \multicolumn{5}{|l|}{ wealth tax variables: } \\
\hline bottom marginal tax rate $t-1$ & $-0.1320^{* * *}$ & $-0.1371^{* * *}$ & -0.0009 & -0.0008 \\
\hline top marginal tax rate ret $_{t-1}$ & $-0.0085^{* * *}$ & $-0.0090^{* * *}$ & $-0.0054^{* * *}$ & $-0.0057^{* * *}$ \\
\hline real exemption $t-1$, singles & $0.1436^{* * *}$ & $0.1495^{* * *}$ & $0.0184^{* * *}$ & $0.0194^{* * *}$ \\
\hline $\begin{array}{l}\text { regional tax assessed house } \\
\text { values, percentage change }\end{array}$ & $0.1665^{* * *}$ & $0.1725^{* * *}$ & $0.0381^{* * *}$ & $0.0397^{* * *}$ \\
\hline $\begin{array}{l}\text { tax exempt small businesses } \\
\text { wealth, share }\end{array}$ & $-0.4753^{* * *}$ & $-0.4950^{* * *}$ & $-0.0209^{* * *}$ & $-0.0229^{* * *}$ \\
\hline \multicolumn{5}{|l|}{ year variable: } \\
\hline post 1990 , indicator & $0.1800^{* * *}$ & $0.1879^{* * *}$ & $-0.0275^{* * *}$ & $-0.0283^{* * *}$ \\
\hline \multicolumn{5}{|l|}{ time invariant variables, } \\
\hline male & & $-0.0114^{* *}$ & & -0.0080 \\
\hline primary education & & $-0.0219^{* * *}$ & & $-0.0317^{* * *}$ \\
\hline upper secondary education & & -0.0019 & & -0.0075 \\
\hline short tertiary education & & $-0.0213^{*}$ & & $-0.0371^{* * *}$ \\
\hline long tertiary education & & 0.0036 & & -0.0029 \\
\hline postgraduate education & & 0.0113 & & 0.0072 \\
\hline other and missing education & & -0.0028 & & 0.0036 \\
\hline place of birth & & yes ${ }^{* * *}$ & & yes $^{* * *}$ \\
\hline year of birth & & yes* & & yes** \\
\hline $\mathrm{n}$ of observations & 473,789 & 473,789 & 445,027 & 445,027 \\
\hline $\mathrm{n}$ of households & 13,660 & 13,660 & 12,840 & 12,840 \\
\hline log likelihood & $-163,746$ & $-186,202$ & $-170,162$ & $-191,816$ \\
\hline pseudo $R^{2}$ & 0.390 & 0.170 & 0.353 & 0.096 \\
\hline partial pseudo $R^{2}$, regressors & 0.144 & & 0.078 & \\
\hline partial pseudo $R^{2}$, fixed effects & 0.266 & & 0.276 & \\
\hline
\end{tabular}

Notes: see Table 3. 
A corresponding $\chi^{2}$-test of all indicators for place of birth indicators taken together also yields a $p$-value of 0.000 . Having been born in northern Sweden, other Nordic countries, Eastern Europe, and the Middle East reduces the probability of being wealthy.

Turning to the fixed effects probit models we might ask: How much do the fixed effects explain compared to the regressors? Table 4 reports partial pseudo $R^{2}$ for regressors and fixed effects. It is clear from the table that the fixed effects are very important.

The underlying estimated coefficients for the age variables are statistically significant. The estimations suggest that there are life-cycle motives for wealth accumulation. The largest estimated partial age effects for being a "millionaire" are for those aged 60. The estimated partial age effects for belonging to the top three percent, on the other hand, are largest for those aged 50.

An important aspect of our fixed effects modeling approach is that it allows gauging the importance of unobserved heterogeneity for the explained variation in the data. Whereas the quite high overall pseudo $R^{2}$ of 35 percent and more for the fixed effects probits is both reassuring and little surprising, the partial pseudo $R^{2}$ for the fixed effects exceeds 26 percent in both models. This suggests that unobserved individual heterogeneity is very important in determining wealth. ${ }^{21}$ Recall that these individual-specific dummy variables may account for a variety of factors, ranging from cohort effects to preference parameters and entrepreneurial skills. Remaining measured regressors contribute much less, depending on model between 8 and 14 percent. Among those, we may distinguish between individual observed heterogeneity (demographics and other taste shifters), on the one hand, and aggregate macroeconomic or tax effects on the other hand. A closer inspection of the size of the marginal effects, and the associated $\chi^{2}$ tests of joint significance, reveals that macroeconomic and tax factors drive absolute wealth much more than relative wealth.

We have calculated age-wealth probability profiles in the same way as for the unconditional models. The random effects probit models provide the basis for the presentation. Using the results from the fixed effects probit models produce almost identical patterns.

The conditional age-wealth probability profile for being a "millionaire" is increasing until the age 76, see the solid line in Figure 8. The dashed line in Figure 8 shows the conditional age-wealth probability profile for belonging to the top three percent. The average probabilities are in this case higher for younger ages. The peak is earlier, at the age of 67. Compared to the unconditional profile in Figure 6, the later peak in Figure 8 is intuitive, given that the probability of being selected

\footnotetext{
${ }^{21}$ The overall pseudo $R^{2}$ is based on a likelihood comparison of the probit model, including all regressors and individual-specific dummy variables, with a probit model including only a single constant. The partial pseudo $R^{2}$ takes the difference between the overall pseudo $R^{2}$ and either a probit model with just regressors but no individual-specific dummies, or a probit model with individual specific dummies and no further regressors. Both partial measures therefore do not add up to the overall pseudo $R^{2}$ measure.
} 
Figure 8: Conditional age-wealth probability profiles, all

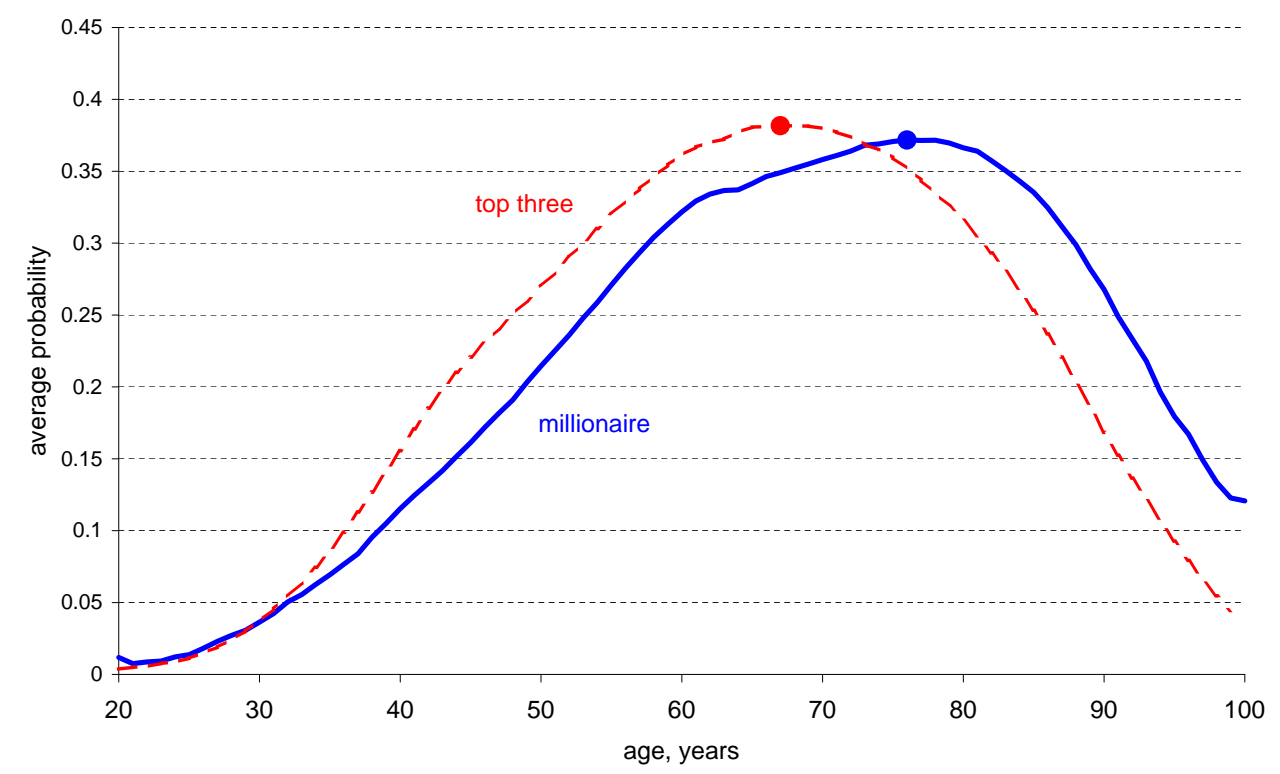

into the sample positively depends on age.

These age-wealth probability patterns are consistent with the life-cycle model in the sense that wealth first increases and then decreases. The peak in wealth, however, occurs when people are some years into retirement and not at the most common retirement ages. The wealth probability is positive even for the very old also here.

Time invariant regressors will, for obvious reasons, drop out of the fixed effects specification and be absorbed by the estimated fixed effects. The estimated fixed effects capture heterogeneity. We will now turn to the correlates of our measured heterogeneity. We regress the estimated individual fixed effects on the time invariant regressors. We use time-averaged values of the other regressors. The estimations reported in Table 5 asks the questions what the correlates of the fixed effects are.

The fixed effect is positively correlated with being single, divorced, and widowed. It is negatively correlated with being an unmarried or a non-cohabiting man. Average age is negatively associated with the fixed effect. There is a positive correlation between the fixed effect and household size while the number of minors is negatively associated with the fixed effect.

We include an indicator for ever reporting business income (or profits and losses). Data are available from 1991 on. Personal wealth and self-employment are strongly positively correlated. This is consistent with returns to entrepreneurial abilities and risk taking. Liquidity constraints, that would likely cause an effect in the same direction, are less likely at the heart of the explanation, given that we study movements into the top of the distribution. 
Table 5: Correlates with fixed effects

\begin{tabular}{|c|c|c|}
\hline & "millionaire" & top three percent \\
\hline \multicolumn{3}{|l|}{ marital status, indicators, averages: } \\
\hline cohabiting & 0.457 & $0.637^{*}$ \\
\hline widow(er) & $1.165^{* * *}$ & $1.171^{* * *}$ \\
\hline divorced & $0.834^{* * *}$ & $0.845^{* * *}$ \\
\hline single & $1.698^{* * *}$ & $1.794^{* * *}$ \\
\hline unmarried $\times$ male & $-0.320^{* * *}$ & $-0.391^{* * *}$ \\
\hline \multicolumn{3}{|l|}{ household variables, averages: } \\
\hline age (in years) & $-0.044^{* * *}$ & $-0.011^{* *}$ \\
\hline age $\times$ number of children & -0.004 & $-0.005^{*}$ \\
\hline number of children 6 or younger & -0.210 & -0.241 \\
\hline number of children $7-12$ & 0.056 & -0.054 \\
\hline number of children $13-17$ & $-0.534^{* *}$ & $-0.571^{* *}$ \\
\hline household size & $0.112^{*}$ & $0.171^{* *}$ \\
\hline log employment income ${ }_{t-1}$ & $1.094^{* * *}$ & $0.914^{* * *}$ \\
\hline $\begin{array}{l}\text { indicator ever had self-employment } \\
\text { income (post 1990) }\end{array}$ & $0.260^{* * *}$ & $0.243^{* * *}$ \\
\hline permanent income uncertainty & $0.007^{* * *}$ & $0.005^{* * *}$ \\
\hline \multicolumn{3}{|l|}{ macro variables, averages: } \\
\hline real GDP growth, percent & 0.072 & -0.104 \\
\hline $\begin{array}{l}\text { stock market index, } \\
\text { percentage changes }\end{array}$ & -0.959 & 1.922 \\
\hline $\begin{array}{l}\text { regional house price indices, } \\
\text { percentage changes }\end{array}$ & 1.009 & 0.936 \\
\hline \multicolumn{3}{|l|}{ wealth tax variables, averages: } \\
\hline bottom marginal tax rate $t-1$ & -3.374 & -6.245 \\
\hline top marginal tax rate ${ }_{t-1}$ & -0.908 & -1.087 \\
\hline real exemption $t-1$, singles & 2.145 & 1.463 \\
\hline $\begin{array}{l}\text { regional tax assessed house values, } \\
\text { percentage changes }\end{array}$ & $-2.854^{* *}$ & -1.301 \\
\hline tax exempt small businesses wealth, share & $6.860^{* *}$ & 4.520 \\
\hline \multicolumn{3}{|l|}{ year variable, average: } \\
\hline post 1990, indicator & $-3.993^{*}$ & -1.206 \\
\hline \multicolumn{3}{|l|}{ time invariant variables, index person: } \\
\hline male, indicator & $-0.055^{* *}$ & -0.036 \\
\hline primary education, indicator & $-0.165^{* * *}$ & $-0.185^{* * *}$ \\
\hline upper secondary education, indicator & -0.053 & -0.063 \\
\hline short tertiary education, indicator & $-0.170^{* *}$ & $-0.218^{* * *}$ \\
\hline long tertiary education, indicator & -0.043 & -0.044 \\
\hline postgraduate education, indicator & -0.045 & -0.038 \\
\hline other and missing education, indicator & -0.078 & -0.032 \\
\hline place of birth, indicators & yes ${ }^{* * *}$ & yes ${ }^{* * *}$ \\
\hline year of birth, indicators & yes** & yes ${ }^{* * *}$ \\
\hline n of households/observations & 13,660 & 12,840 \\
\hline $\operatorname{adj} R^{2}$ & 0.349 & 0.165 \\
\hline correlation with dep. variable & 0.376 & 0.476 \\
\hline
\end{tabular}

Notes: see Table 3. 
It is clear from the table that employment income is positively correlated with the estimated fixed effect. There is a positive correlation between the permanent income uncertainty and the fixed effect. The macro variables are not correlated with the fixed effect.

The estimated correlations between the fixed effects and these measurable characteristics predict a variance in fixed effects that corresponds to about a third of the total variance of the fixed effects looking at the $R^{2}$-measures for being a "millionaire". The $R^{2}$-measures are lower for belonging to the top three percent.

\subsection{Conditional models: the cohort born during the 1940s}

We limit the sample to households with index persons born 1940-1950 in this subsection. These household index persons were 18-28 years old in 1968 and 55-65 years old in 2005 .

Table 6 reports the estimation results for the cohort born during the 1940s of being a "millionaire" and belonging to the top three percent. Most estimated effects do not differ qualitatively from those reported in Table 4. There are, however, some important exceptions to this. The estimated effects of household size and the number of minors are no longer statistically significant here.

These models also suggest that there are precautionary motives for wealth accumulation. The estimated coefficients for permanent income uncertainty, however, are not statistically significant here.

The bottom marginal tax rate has a statistically significant negative impact on the probability of being a "millionaire". The impact on belonging to the top three percent is, on the other hand, positive and statistically significant. This suggests that this tax rate affects absolute and relative wealth very differently.

The underlying estimated coefficients for the age variables are statistically significant. The largest estimated partial age effects for being a "millionaire" and for belonging to the top three percent are for those aged 50. For being a "millionaire" this differs from the total sample where the largest estimated partial age effect, on the other hand, is for those aged 60. These estimations also suggest that there are life-cycle motives for wealth accumulation.

The calculated age-wealth probability profile is increasing over the whole age range up to 64 years. This is clear from Figure 9. The solid line in the figure shows the conditional probabilities, the maximum probability is 0.65 . The maximum probability is considerably higher for this cohort than for the total sample. The dashed line in Figure 9 shows the age-wealth probability profile for being in the top three percent. The maximum probability is 0.52 . 
Table 6: Probit models, average partial effects, the 1940s cohort

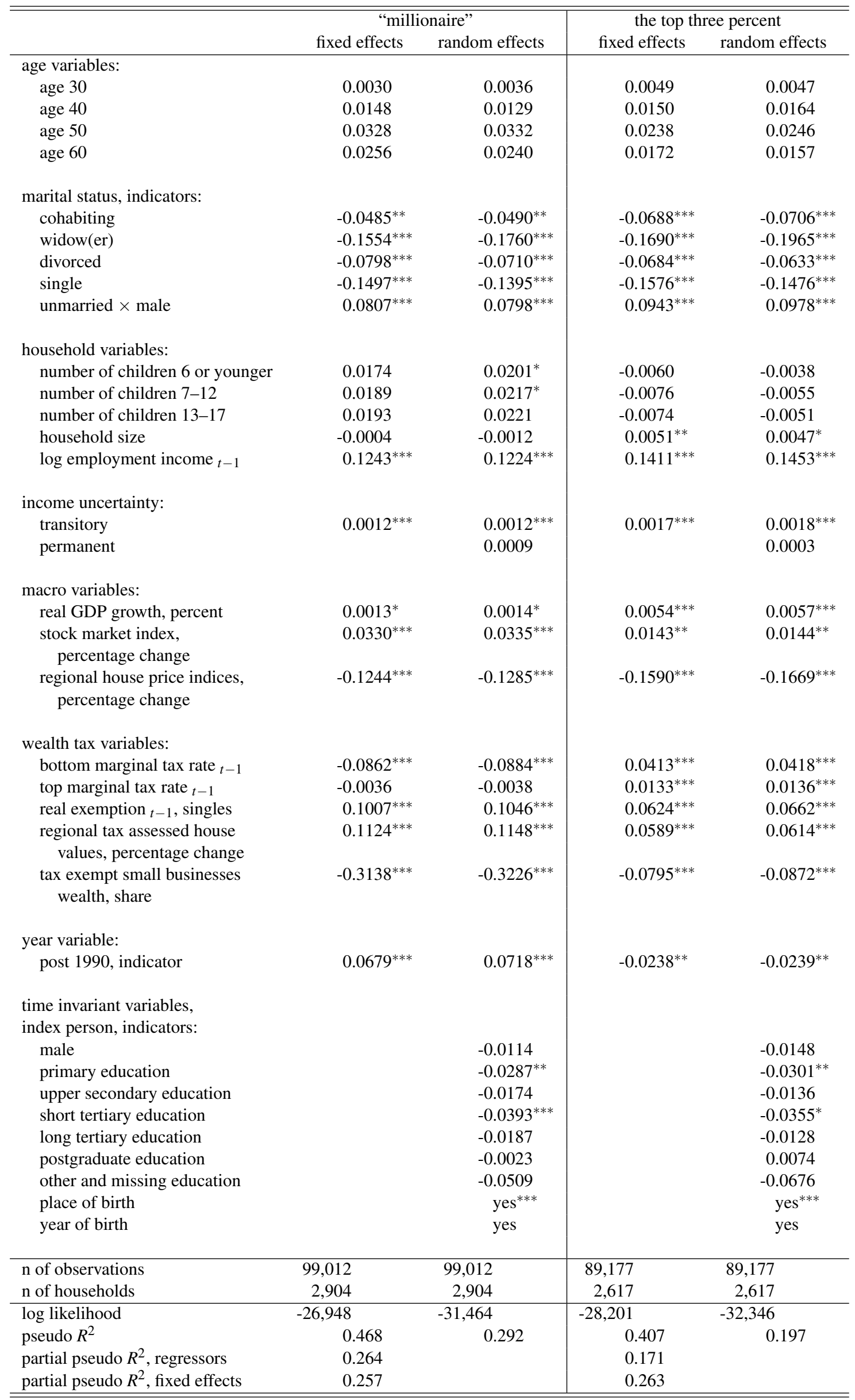

Notes: see Table 3. 
Figure 9: Conditional age-wealth probability profiles, the 1940s cohort

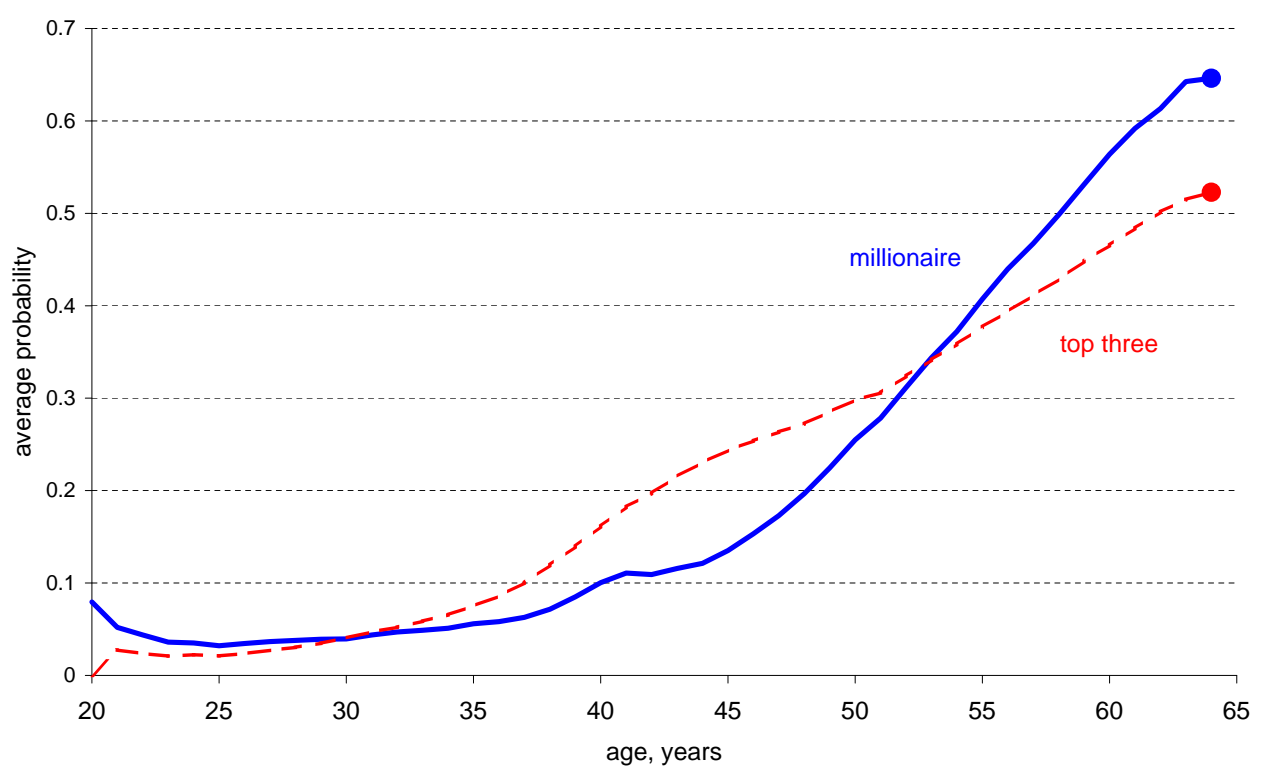

Table 7 reports the correlates of the fixed effects, our measured heterogeneity. Most estimated effects do not differ qualitatively from those reported in Table 5. There are, however, two important exceptions to this: First, the estimated effect of employment income is no longer statistically significant here. Second, permanent income uncertainty is no longer significant here. It can also be noted that average age and the year of birth indicators are not significant here when the sample is constrained to only include households with index persons born in the 1940s.

The indicator for ever reporting business income (or profits and losses) is statistically significant also here. Personal wealth and self-employment are strongly positively correlated. 
Table 7: Correlates with fixed effects, the 1940s cohort

\begin{tabular}{|c|c|c|}
\hline & "millionaire" & top three percent \\
\hline \multicolumn{3}{|l|}{ marital status, indicators, averages: } \\
\hline cohabiting & 0.154 & 0.533 \\
\hline widow(er) & $1.604^{* * *}$ & $1.564^{* * *}$ \\
\hline divorced & 0.400 & $0.690^{*}$ \\
\hline single & $1.878^{* * *}$ & $1.896^{* * *}$ \\
\hline unmarried $\times$ male & $-0.362^{* * *}$ & $-0.407^{* * *}$ \\
\hline \multicolumn{3}{|l|}{ household variables, averages: } \\
\hline age (in years) & 0.540 & 0.500 \\
\hline age $\times$ number of children & 0.014 & 0.017 \\
\hline number of children 6 or younger & $-1.133^{*}$ & $-1.153^{*}$ \\
\hline number of children $7-12$ & -0.486 & -1.458 \\
\hline number of children $13-17$ & $-2.697^{* * *}$ & $-2.338^{* *}$ \\
\hline household size & $0.413^{* * *}$ & $0.465^{* * *}$ \\
\hline log employment income $t_{t-1}$, average & -0.043 & -0.148 \\
\hline $\begin{array}{l}\text { indicator ever had self-employment } \\
\text { income (post 1990) }\end{array}$ & $0.206^{* * *}$ & $0.190^{* * *}$ \\
\hline permanent income uncertainty & 0.003 & 0.000 \\
\hline \multicolumn{3}{|l|}{ macro variables, averages: } \\
\hline real GDP growth, percent & -0.319 & -0.076 \\
\hline $\begin{array}{l}\text { stock market index, } \\
\text { percentage changes }\end{array}$ & 3.930 & $11.322^{* *}$ \\
\hline $\begin{array}{l}\text { regional house price indices, } \\
\text { percentage changes }\end{array}$ & -3.908 & -3.527 \\
\hline \multicolumn{3}{|l|}{ wealth tax variables, averages: } \\
\hline bottom marginal tax rate ${ }_{t-1}$ & $-24.739^{* *}$ & $-23.455^{* *}$ \\
\hline top marginal tax rate $t-1$ & 2.846 & 2.709 \\
\hline real exemption $t-1$, singles & -1.565 & -2.442 \\
\hline $\begin{array}{l}\text { regional tax assessed house values, } \\
\text { percentage changes }\end{array}$ & -0.759 & -0.694 \\
\hline tax exempt small businesses wealth, share & 0.737 & -1.485 \\
\hline \multicolumn{3}{|l|}{ year variable, average: } \\
\hline post 1990 , indicator & -1.272 & 1.755 \\
\hline \multicolumn{3}{|l|}{ time invariant variables, index person: } \\
\hline male, indicator & -0.074 & -0.078 \\
\hline primary education, indicator & $-0.200^{* *}$ & $-0.193^{* *}$ \\
\hline upper secondary education, indicator & $-0.167^{*}$ & -0.099 \\
\hline short tertiary education, indicator & $-0.271^{* *}$ & -0.191 \\
\hline long tertiary education, indicator & -0.138 & -0.059 \\
\hline postgraduate education, indicator & -0.092 & -0.042 \\
\hline other and missing education, indicator & -0.353 & -0.395 \\
\hline place of birth, indicators & yes $^{* * *}$ & yes $^{* * *}$ \\
\hline year of birth, indicators & yes & yes \\
\hline $\mathrm{n}$ of households/observations & 2,904 & 2,617 \\
\hline $\operatorname{adj} R^{2}$ & 0.175 & 0.156 \\
\hline correlation with dep. variable & 0.389 & 0.437 \\
\hline
\end{tabular}

Notes: see Table 3. 


\section{Conclusions}

With increasing availability of suitable micro data, the recent economic literature has seen a surge in interest in studying distributional issues and implications of top incomes over the past few years. In addition, there is some revived interest in studies on wealth mobility.

We add to this literature by studying individual wealth mobility over the entire life cycle exploiting long individual time series of household wealth. We use a large administrative sample from Sweden. The period under study covers the years 1968-2005. We can track many households that are continuously in the sample.

The wealth data are heavily censored from below. This is because their values originate from wealth tax registers. The wealth tax in Sweden (repealed from 2007) was associated with relatively high exemption levels. This leaves only a small fraction (between 3.4 and 13.1 percent) of households observed with wealth in any one cross section. We do, however, capture the top of the wealth distribution. This is very important for determining wealth aggregates. A large fraction of households pay wealth taxes at least at some point during their life cycles. 34 percent do so if we condition on those that are in the sample every year from 1968 to 2005. This is important as it makes it possible to study if the data are consistent with the predictions from the life-cycle model.

Whereas the wealth information available in the tax data is restricted, we can shed new light on the study of wealth mobility at the individual level. Due to heavy censoring, we confine ourselves to looking at changes over time in binary indicators. We, therefore, study movements in and out of the top three percent of the wealth distribution and across an absolute wealth threshold that we refer to as "millionaires".

So, who is wealthy? Probably an individual in his 60s, married, living in a big household and with more than twelve years of education. He was born in the capital city region. The employment income of the household is high but variable. The macroeconomic environment is characterized by economic growth, increasing stock market prices, and increasing house values.

Our main results are:

- We find considerable movements into and within the top percents in the wealth distribution. This is not quite consistent with previous results for Sweden presented by Klevmarken (2004), but he studies other segments of the wealth distribution than we do. The average duration in the top three percents of the wealth distribution is about 6 years conditional on ever belonging to the top three percent.

- Intragenerational wealth mobility has varied over time. Our estimations suggests that wealth mobility increased during the 1970s and 1980s in a relative sense. The movements in the rankings in the top of the wealth distribution, in other words, became more frequent. The peak in mobility coincides with the 
deregulation of the Swedish financial markets during the second half of the 1980s. Wealth mobility has decreased since then. The number of wealthy and the concentration of wealth have increased at the same time.

- We find age-wealth probability patterns consistent with the life-cycle model of savings and wealth accumulation. The patterns are consistent with the life-cycle motives for savings in the sense that wealth first increases and then decreases. The peak in the probability of being wealthy occurs when people are about 65 years old. This is close to the age when retiring for most.

- The probability of being wealthy is higher when households experience high income uncertainty. This is consistent with precautionary motives for savings and wealth accumulation, although effects are small. 


\section{References}

Attanasio, O. P. and Hoynes, H. W. (2000). Differential mortality and wealth accumulation. Journal of Human Resources, 35(1):1-29.

Carroll, C. D. and Samwick, A. A. (1997). The nature of precautionary wealth. Journal of Monetary Economics, 40(1):41-71.

Davies, J. B. (2008). An overview of personal wealth. In Davies, J. B., editor, Personal Wealth from a Global Perspective, UNU-WIDER Studies in Development Economics, chapter 1, pages 1-23. Oxford University Press, Oxford.

Davies, J. B., Sandström, S., Shorrocks, A., and Wolff, E. N. (2008). The world distribution of household wealth. In Davies, J. B., editor, Personal Wealth from a Global Perspective, UNU-WIDER Studies in Development Economics, chapter 19, pages 395-418. Oxford University Press, Oxford.

Davies, J. B. and Shorrocks, A. F. (1999). The distribution of wealth. In Atkinson, A. B. and Bourguignon, F., editors, Handbook of Income Distribution, pages 605-675. Elsevier, Amsterdam.

Deaton, A. S. and Paxson, C. H. (1994). Saving, growth, and aging in Taiwan. In Wise, D. A., editor, Studies in the Economics of Aging, chapter 9, pages 331361. University of Chicago Press, Chicago.

Dell, F., Piketty, T., and Saez, E. (2007). Income and wealth concentration in Switzerland over the twentieth century. In Atkinson, A. B. and Piketty, T., editors, Top Incomes over the Twentieth Century: A Contrast between European and English-speaking Countries. Oxford University Press, Oxford.

Dynan, K., Skinner, J., and Zeldes, S. (2004). Do the rich save more? Journal of Political Economy, 112(2):397-444.

Edin, P.-A. and Fredriksson, P. (2000). LINDA - Longitudinal INdividual DAta for Sweden. Working Paper 2000:19, Department of Economics, Uppsala University.

Greene, W. H. (2004). The behaviour of the maximum likelihood estimator of limited dependent variable models in the presence of fixed effects. Econometrics Journal, 7:98-119.

Hochguertel, S. and Ohlsson, H. (2011). Wealth mobility and dynamics over entire individual working life cycles. Working Paper No 1301, European Central Bank.

Hurst, E., Luoh, M. C., and Stafford, F. P. (1998). Wealth dynamics of American families, 1984-94. Brookings Papers on Economic Activity, (1):267-337.

Jappelli, T. and Pistaferri, L. (2000). The dynamics of household wealth accumulation in Italy. Fiscal Studies, 21(2):269-295. 
Jianakoplos, N. A. and Menchik, P. L. (1997). Wealth mobility. Review of Economics and Statistics, 79(1):18-31.

Keister, L. A. (2005). Getting Rich: America's New Rich and How They Got That Way. Cambridge University Press, Cambridge and New York.

Klevmarken, N. A. (2004). On the wealth dynamics of Swedish families, 1984-98. Review of Income and Wealth, 50(4):469-491.

Klevmarken, N. A., Lupton, J. P., and Stafford, F. P. (2003). Wealth dynamics in the 1980s and 1990s: Sweden and the United States. Journal of Human Resources, 38(2):322-353.

Kopczuk, W. and Saez, E. (2004). Top wealth shares in the United States, 19162000: Evidence from estate tax returns. National Tax Journal, 57(2):445-487.

Leland, H. E. (1968). Saving and uncertainty: The precautionary demand for saving. Quarterly Journal of Economics, 82(3):465-473.

Modigliani, F. and Brumberg, R. H. (1954). Utility analysis and the consumption function: an interpretation of cross-section data. In Kurihara, K. K., editor, Post-Keynesian Economics, pages 388-436. Rutgers University Press, New Brunswick, NJ.

Mundlak, Y. (1978). On the pooling of time series and cross section data. Econometrica, 46(1):69-85.

Neyman, J. and Scott, E. L. (1948). Consistent estimates based on partially consistent observations. Econometrica, 16(1):1-32.

Ohlsson, H., Roine, J., and Waldenström, D. (2008). Long-run changes in the concentration of wealth: An overview of recent findings. In Davies, J. B., editor, Personal Wealth from a Global Perspective, UNU-WIDER Studies in Development Economics, chapter 3, pages 42-63. Oxford University Press, Oxford.

Piketty, T., Postel-Vinay, G., and Rosenthal, J. L. (2006). Wealth concentration in a developing economy: Paris and France, 1807-1994. American Economic Review, 96(1):236-256.

Quadrini, V. (2000). Entrepreneurship, saving, and social mobility. Review of Economic Dynamics, 3(1):1-40.

Roine, J. and Waldenström, D. (2009). Wealth concentration over the path of development: Sweden, 1873-2006. Scandinavian Journal of Economics, 111(1):151187.

Selin, H. (2009). The rise in female employment and the role of tax incentive: An empirical analysis of the Swedish individual tax reform of 1971. Working Paper 
2009:3, Uppsala Center for Fiscal Studies, Department of Economics, Uppsala University.

Shorrocks, A. F. (1975). The age-wealth relationship: A cross-section and cohort analysis. Review of Economics and Statistics, 57(2):155-163.

Shorrocks, A. F. (1978a). Income inequality and income mobility. Journal of Economic Theory, 19:376-393.

Shorrocks, A. F. (1978b). The measurement of mobility. Econometrica, 46(5):1013-1024.

Steckel, R. H. and Krishnan, J. (2006). The wealth mobility of men and women during the 1960s and 1970s. Review of Income and Wealth, 52(2):189-212. 


\section{A Details on data}

\section{A.1 Samples}

The data come in two sub-samples, the $P$ - (panel) and the $F$-sample (family). For the P-sample (1968-1999), an initial sample of 300,000 households (700,000 individuals) was drawn in 1994. A household in the data set is a group of people treated as a taxable unit. For the vast majority of cases, this coincides with a residential household or a family.

All members of these 1994 households were then followed through time, backwards until 1968, and assigned the same household number as the 1994 one if they were members of that same tax household in the respective year. For those members who joined the 1994 households in other years, a different household number was assigned before joining. The data also tracks those joining members through time when they are not member of a 1994 household. Likewise, the data were extended beyond 1994 until 1999, using a similar sampling scheme. This implies that the change in the number of households and individuals is closely following the development of the entire residential population in the country for the period 1968-1999.

In the F-sample (from 1991 onwards) the sampling unit is a "family": persons living at the same address according to the population register. Since there may be several sub-households within a "family" that are treated as separate taxable units, and since members of the same tax households may live at different addresses, it may be that the definitions of "households" in the P-sample and of "family" in the F-sample do not coincide. A "family" is, on average, slightly larger than a "household".

Each household member included in the data has an individual identifier. Within a household, one member is the designated index person. Usually, household and person identifier coincide for this person. We can use this index person to link both $\mathrm{P}$ - and F-samples over time.

We identify the head of household as the data index person. The definition changes between P- and F-samples. In 1999, identifiers for household/family are the same, but the correspondence in 1991-1998 between the household/family identifiers is not perfect.

The index person in the F-files corresponds (with very few exceptions) to the oldest member in the household, while the index person in the P-files corresponds to the oldest male in the the household (except for women-only households, and a few other cases).

Hence, we recompute the household identifier (hhid) for the P-files based on the oldest member and assign as index person (head of household) the one whose person identifier is equal to hhid, if aged 18 and above.

Especially in the 1980's there are a small number of households without head (children-only households); if these cannot be matched successfully, we do not assign a head of household; if they can, we attribute a person that is recorded in the 
household in other years.

We further identify personal characteristics of the household by those of the index person (age, sex, education, etc.).

\section{A.2 A short account of imputations}

The original LINDA files come with a number of variables from various registers requiring integration into consistent time series for our purposes. The following very briefly lists some of the main imputations and checks performed on the data.

\section{- Region of Birth and Residence:}

Over the years, various labels have been used for country (residents born abroad) or county (Swedish-born residents) of birth. County boundaries have changed.

In a few years, county of residence is unavailable. We can use census information for 1970, and we can rely on information from other variables for other years, such as the local tax authority code, to determine the county of residence in a given year. Between years, we impute missings from adjacent years.

For those born abroad, we distinguish the following regions of birth: Scandinavia, other Western Europe, Eastern Europe (inc. former USSR), the Middle East, and the rest of the world. In a very small amount of cases changes of origin of birth are recorded in the data. We use the latest information on record to impute missings and inconsistencies, after aggregation into broad categories.

\section{- Tax units:}

To understand the accuracy of wealth information available in the data, we can use the tax schedule to impute taxes paid from wealth reported. We can then compare the imputed tax liability with the actual taxes paid reported in the data. However, the taxes paid will depend on the tax unit within the household, so that we first need to determine which members form a tax unit within a household in a particular year.

Assessment: with a tolerance of SEK 100, we calculate the correct tax amounts (if positive) in about 97 percent of all cases. This suggests that the tax units are largely correctly identified. The share of households with correct tax amounts varies between years, from a low of 94.84 percent (2002) to a high of 99.36 percent (1974).

Figure A.1 shows how wealth tax revenue calculated using the households in the LINDA samples corresponds to total wealth tax revenue reported by the Swedish National Financial Management Authority. It is clear from the figure that tax revenue according to the micro data tracks total tax revenue surprisingly well. 
Figure A.1: Wealth tax revenue: Actual and calculated from the LINDA samples

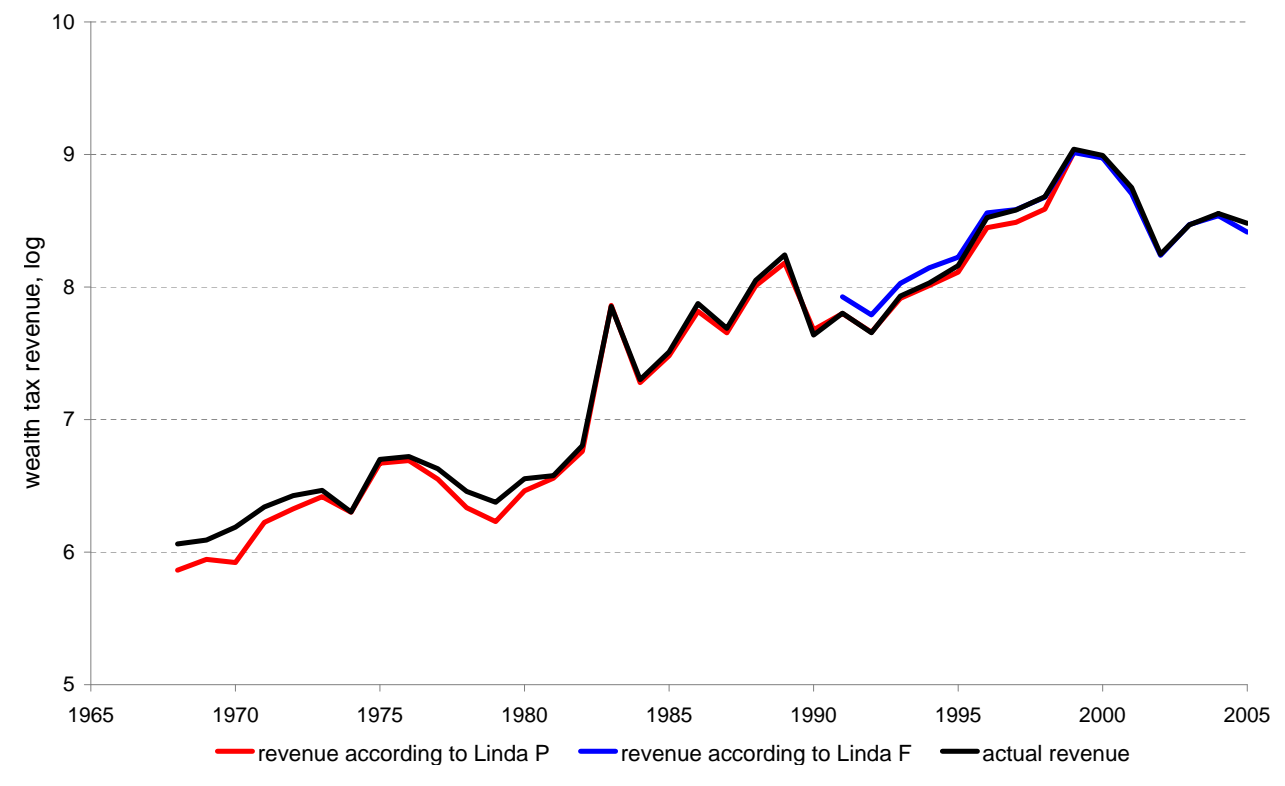




\section{- Education:}

In LINDA, education is available only from 1990 on, at different levels of recording/aggregation and completeness. In 1990 there is an indicator from 1 to 7 for different levels, in 1991-1999 there is a 5-digit code, recording both education type and vocational orientation, in 2000-2005 there is a 3-digit code. Coding referred to the SUN system for years before 2000, and to SUN2000 from year 2000 onwards. We adjusted all education levels to the six classes defined in SUN2000 for all years. This also holds for education levels determined in 1970, for which we use separately available census data.

There are, thus, two problem areas for education information in our data: one is the large gap between 1971 and 1989. The other is inconsistencies in the time series, among which larger than expected jumps between records from adjacent years, and decreasing education levels between years.

We want to impose on the data that education is weakly monotonically increasing in age for each individual. We impute incomplete individual histories, making simplifying assumptions, and use-where available - information on the year of attainment of a particular level. The following table gives the education coding according to the SUN2000 system,

\begin{tabular}{rllr}
\hline level & SUN 2000, corresponds to ISCED 97 & we use the term & max. age \\
\hline 0 & $\begin{array}{l}\text { pre-primary education } \\
\text { primary and lower secondary education, } \\
\text { less than 9 years } \\
\text { primary and lower secondary education, } \\
9 \text { (or 10) years }\end{array}$ & $\begin{array}{l}\text { pre-school education } \\
\text { primary education }\end{array}$ & 15 \\
3 & $\begin{array}{l}\text { lower secondary education } \\
\text { upper secondary education }\end{array}$ & upper secondary education & 16 \\
4 & $\begin{array}{c}\text { post-secondary education, } \\
\text { less than two years } \\
\text { post-secondary education, } \\
\text { two years or longer } \\
\text { postgraduate education }\end{array}$ & short tertiary education & 22 \\
& long tertiary education & 27 \\
& postgraduate education & 32 \\
\hline
\end{tabular}

where level 0 is never recorded in the data. The column 'max. age' indicates the age threshold beyond which we assume no change of education level anymore, unless found explicitly in the data.

The imputation then proceeds as follows: In a first step, all those that need special attention (those where education level drops with age and those whose education level jumps particularly strongly) were identified, and separated from those that only had incomplete series.

In a second step, all individuals were identified who had no education information whatsoever. For these, a pure age imputation has been done for levels 0 and 1.

For others, we make a distinction according to whether the year of attaining the reported education level is available. If so, we use backward updating of levels until the earliest reported year: starting in 2005, we attribute the 
education level reported in that year to all years backwards until the year of attainment. We then go back, year by year, to update missing information.

Those that do not have any information on the year of educational attainment, or those who after using the year information still had incomplete histories, have been imputed on an age/max. education level basis. Here, we interpret more recent information as being more accurate. Particular problems were encountered for some observations in 1970 and 1990, that we first set to missing before imputing.

In a third step, we deal-in a similar way-with problematic cases (sudden jumps and negative education level changes). Again, observations in 1970 and 1990 were associated with many of the problematic cases and were set to missing before being imputed.

In a fourth step, we combine all the information and imputed values from before.

Overall, some 19 million person-year observations were missing in the original data, of which close to 17 million have been imputed. Only a small number of observations (less than 0.5 percent of the data) have their original values changed or set to missing due to inconsistencies. About 9 percent of all observations keep a missing value that could not be imputed.

\section{- Number of Children:}

Large differences in the overall number of children recorded per household can arise between the years. This is particularly true for P-files, and to lesser extent for F-files. Children without any wealth of their own do not pose a problem for our household wealth measures, but the number of children below 18 , used as a regressor, varies.

No attempt has been undertaken to impute the number of children age 18 and above per household, and we do not use such information.

The imputation makes the following assumptions: (1) all children ever reported have been, after they were born, present in some sampled household at some stage, and (2) children aged 17 or younger that cease to be reported continue to be in the household they were last observed until they turn 18 ; in particular, no child dies.

Assumption (1) may introduce errors (overcounts) for children that were (a) step-children, adopted or foster-children entering the household at age $>0$, or (b) left the household temporarily with one of the parents, say. Assumption (1) also applies to dealing with observational gaps:

Suppose a child is observed in 1971 and before, not observed in 1972-1975 and observed in 1976-1980. If it is observed in 1971 and 1976 in the same household, it is attributed to that household also during the gap years. If it is observed in a different household, we assume it belongs to the 1976household from 1972 on. 
Assumption (2) is possibly more problematic as a child might leave the household due to (a) death, (b) school elsewhere, and (c) the household splitting. Of those reasons, only (c) may be of practical relevance.

Imputations (1) and (2) misattribute children status to below-age-18 nonchildren household members. Presumably this is a minor issue.

Assessment: the distribution of the number of children in different age classes looks a lot smoother over time after the imputation than before the imputation. The total number of children added this way is larger during early years (1968-1970) than during later years, and totals about 5 percent for the P-files and 2 percent for the F-files.

\section{A.3 Income uncertainty}

We attempt to disentangle the permanent from the transitory variance of earnings. In a first step, we split the data by education level $j$ and regress transformed noncapital income (a measure of earnings before taxes, but including benefits, etc.) on aggregate productivity growth $g$ and an individual-specific linear age (or time) trend. That is, the model we estimate is

$$
\tilde{y}_{i t}=g_{t} \gamma_{j}+a_{i t} \alpha_{i}+\eta_{i}+\varepsilon_{i t} \quad \forall j
$$

where $\tilde{y}_{i t}$ is the inverse hyperbolic sine transformation applied to our income measure $y_{i t}$. This transformation is similar to a logarithm, but allows for non-positive incomes. $a_{i t}$ denotes age, $\varepsilon_{i t}$ is an idiosyncratic shock, and $\eta_{i}$ is a fixed individualspecific constant. $\alpha_{i}$ is likewise an estimated, fixed individual-specific parameter. This way of modeling allows each household to have their own age-income profile, and hence allows for a large degree of heterogeneity in the population. We, thus, do not specify global income processes, but rather rely on within-household identification. We assume that conditional on the fixed effect and general income growth (we use real GDP growth for $g_{t}$ ), the individual household knows about its parameter $\alpha_{i}$ and, therefore, can predict mean income from age. Note that the fixed effect formulation allows implicitly for all kinds of correlations with unobserved fixed factors.

In a second step, we determine the residual $\hat{r}_{i t}$ as the difference between the observed and the predicted value of income, $\hat{y}_{i t}=g_{t} \hat{\gamma}_{j}+a_{i t} \hat{\alpha}_{i}+\hat{\eta}_{i}$. The variance of permanent income uncertainty is then captured by the within-household variance of $\hat{r}_{i t}$, and the variance of transitory income shocks is calculated on 3 adjacent within-household observations of $\hat{r}_{i t}$, and, therefore, varies over time.

The procedure we use is an alternative to the well-known approach advocated by Carroll and Samwick (1997). These authors first postulate a process for log permanent income (random walk with drift), and then back out the permanent and transitory variances from a number of time-differences of income given the model. Applied to our data, this procedure results not only in negative estimates of transitory variances, but also in almost perfect correlation between permanent and 
transitory variance estimates in the cross section. Note that we use similar income measures as Carroll and Samwick (1997), but base our estimates on longer time series (38 years as opposed to 7).

\section{A.4 Descriptive regressions}

The nonlinear trend imposed on Figure 4 is obtained from the regression displayed in Table A.1, column 1. The adjusted series and the trends in Figure 5 are the regressions presented in column 2-4 in Table A.1.

Table A.1: Descriptive regressions

\begin{tabular}{|c|c|c|c|c|}
\hline dependent variable: & $\begin{array}{l}\text { Shorrocks' } \\
\text { measure }\end{array}$ & \multicolumn{3}{|c|}{ percentage share remaining in: } \\
\hline trend & $\begin{array}{l}0.0147^{* * *} \\
(0.0029)\end{array}$ & $\begin{array}{l}-1.66^{\text {*** }} \\
(0.39)\end{array}$ & $\begin{array}{l}-1.61^{* * *} \\
(0.30)\end{array}$ & $\begin{array}{l}-1.12^{* * *} \\
(0.20)\end{array}$ \\
\hline $\operatorname{trend}^{2} / 10$ & $\begin{array}{l}-0.00347^{* * *} \\
(0.00075)\end{array}$ & $\begin{array}{l}0.386^{* * *} \\
(0.104)\end{array}$ & $\begin{array}{l}0.379^{* * *} \\
(0.080)\end{array}$ & $\begin{array}{l}0.271^{* * *} \\
(0.053)\end{array}$ \\
\hline $\begin{array}{l}\text { change in assessment of single } \\
\text { family houses' tax values }\end{array}$ & $\begin{array}{l}0.00669^{* * *} \\
(0.00095)\end{array}$ & $\begin{array}{l}-0.819^{* * *} \\
(0.131)\end{array}$ & $\begin{array}{l}-0.828^{* * *} \\
(0.100)\end{array}$ & $\begin{array}{l}-0.346^{* * *} \\
(0.066)\end{array}$ \\
\hline $\begin{array}{l}\text { change in small businesses' } \\
\text { wealth tax values }\end{array}$ & $\begin{array}{l}-0.00420^{* * *} \\
(0.00091)\end{array}$ & $\begin{array}{l}0.533^{* * *} \\
(0.125)\end{array}$ & $\begin{array}{l}0.459^{* * *} \\
(0.096)\end{array}$ & $\begin{array}{l}0.261^{* * *} \\
(0.064)\end{array}$ \\
\hline $\begin{array}{l}\text { change in exemption difference } \\
\text { between couples and singles }\end{array}$ & $\begin{array}{l}0.148^{* *} \\
(0.056)\end{array}$ & $\begin{array}{l}-34.2^{* * *} \\
(7.74)\end{array}$ & $\begin{array}{l}-5.45 \\
(5.93)\end{array}$ & $\begin{array}{l}-4.46 \\
(3.94)\end{array}$ \\
\hline constant & $\begin{array}{l}0.217^{* * *} \\
(0.024)\end{array}$ & $\begin{array}{l}65.1^{* * *} \\
(3.30)\end{array}$ & $\begin{array}{l}77.4^{* * *} \\
(2.53)\end{array}$ & $\begin{array}{l}92.8^{* * *} \\
(1.68)\end{array}$ \\
\hline$F(5,31)$ & 19.26 & 17.98 & 22.78 & 14.16 \\
\hline prob $>F$ & 0.000 & 0.000 & 0.000 & 0.000 \\
\hline$R^{2}$ & 0.756 & 0.744 & 0.786 & 0.695 \\
\hline $\operatorname{adj} R^{2}$ & 0.717 & 0.702 & 0.752 & 0.646 \\
\hline RMSE & 0.0427 & 5.891 & 4.514 & 2.997 \\
\hline number of observations & 37 & 37 & 37 & 37 \\
\hline
\end{tabular}




\section{B The Swedish wealth tax}

The Swedish wealth tax in its modern form was introduced in 1948 when there was an extensive tax reform. It has never been a major source of government revenue. The main arguments for it have been equity and redistribution. The wealth tax was repealed from 2007 by the then newly elected right-wing government. ${ }^{22}$ The tax remains a hot political topic, the Social Democrats said that they would reintroduce the tax if they regained power in the 2010 parliamentary election. The Social Democrats, however, lost the election.

The main features of the wealth tax were unchanged over the main observation period, 1968-2005. It differed from other personal taxes in that it was levied at the household level and not at the individual level. This was, in other words, the only example when the household, and not the individual or the firm, was the unit of taxation. ${ }^{23}$

The net wealth of the adult members of the household was added together with the net wealth of the minor children of the household. The tax base was a comprehensive measure of household net wealth (including real assets and financial assets minus debts). ${ }^{24}$ Household tax liability was subsequently individualized according to the net wealth share of the individual within the household.

Taxable wealth did not include pension wealth in the sense that the value of future public and occupational pensions were not included, neither were savings in tax deferred pension savings accounts. The values of cars, boats, works of art, and life insurance were not included. In addition, there was far from complete coverage of assets abroad. The tax base primarily consisted of assets for which it was possible to get third party reporting from banks, financial institutions, public agencies, etc.

The wealth tax system was conceptually simple. There was a generous exemption level, exempting, on average, more than 90-95 percent of all households from paying any taxes at all. We refer to this as tax bracket zero with a marginal tax rate of zero. As of 2001, households with two adult spouses got a higher exemption than single households.

Subsequently, (progressively) positive marginal tax rates were applied to subsequent brackets. In later years, the system was simplified to a two-bracket system with a zero-marginal rate in bracket zero and a single positive marginal tax rate thereafter. Tax reforms were discontinuous but frequent and marginal. In every few years bracket limits have been adjusted, marginal rates have been changed, or the number of tax brackets has been varied. In addition, in all years between nom-

\footnotetext{
${ }^{22}$ The Swedish repeal of the wealth tax followed similar repeals in Austria (from 2001), Denmark (from 1997), Finland (from 2006), and Italy (from 2005).

${ }^{23}$ The personal income tax was joint between spouses before 1971. From 1966 couples could, however, apply to be treated as single filers, see Selin (2009).

${ }^{24}$ The owner to the international clothing retail company H\&M threatened to leave the country in 1990s. The government, therefore, introduced some new valuation principles that in practice meant that a handful superrich basically became tax exempt.
} 
inal changes, the real value of the exemption threshold was affected by inflation (fiscal drag).

Table B.1 reports the main aspects of the Swedish wealth tax exemptions and rates during the period 1948-2006.

Table B.2 presents the number and the share of households in the LINDA data set paying the wealth tax each year. The mean wealth of these households is also reported. The number and the share of households classified as "millionaires" are also given in the table in an analogous way. The table also presents the mean wealth of the "millionaires". The table finally lists the number of households in the top three percent of the wealth distribution and their mean wealth. 


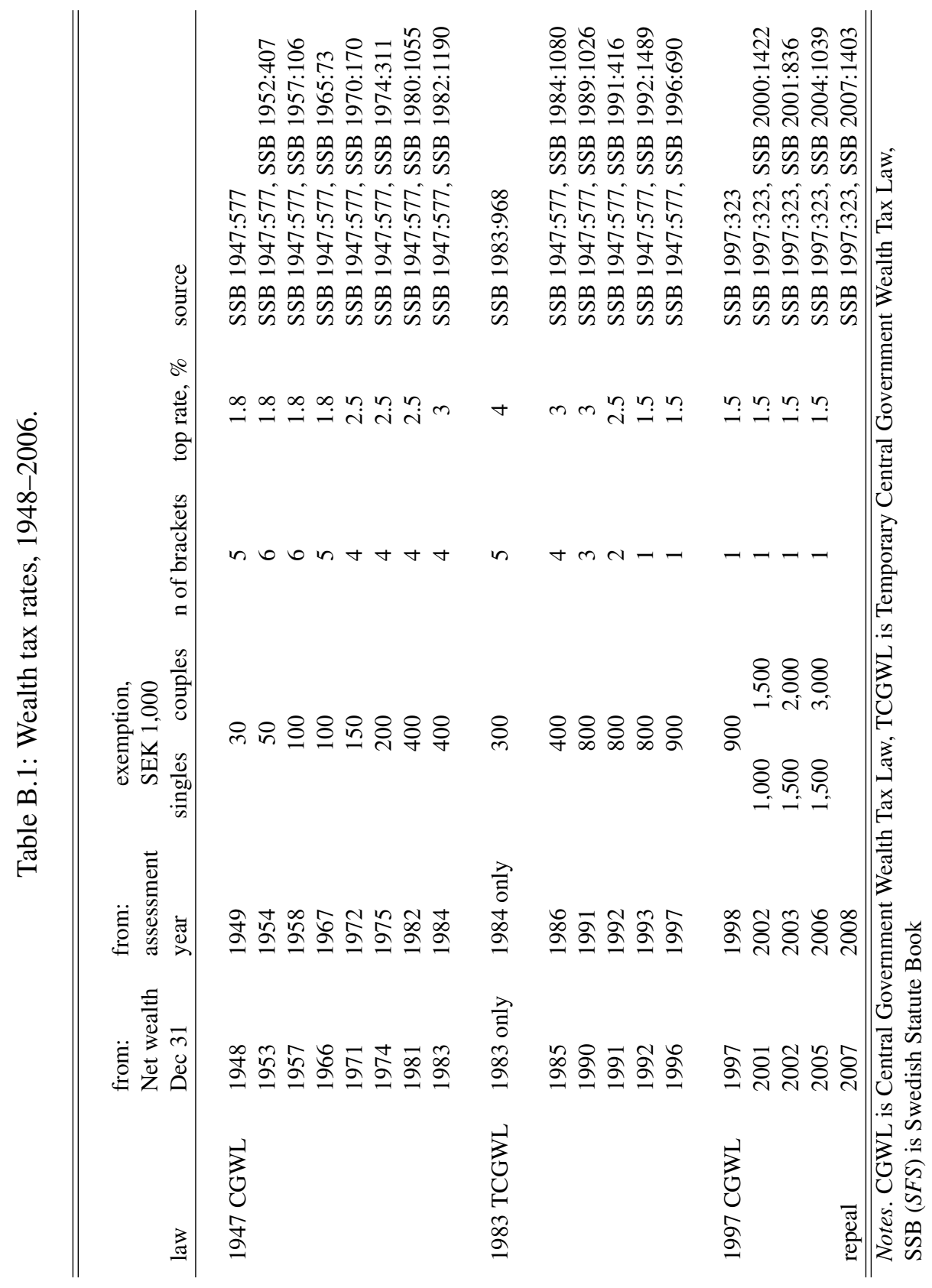




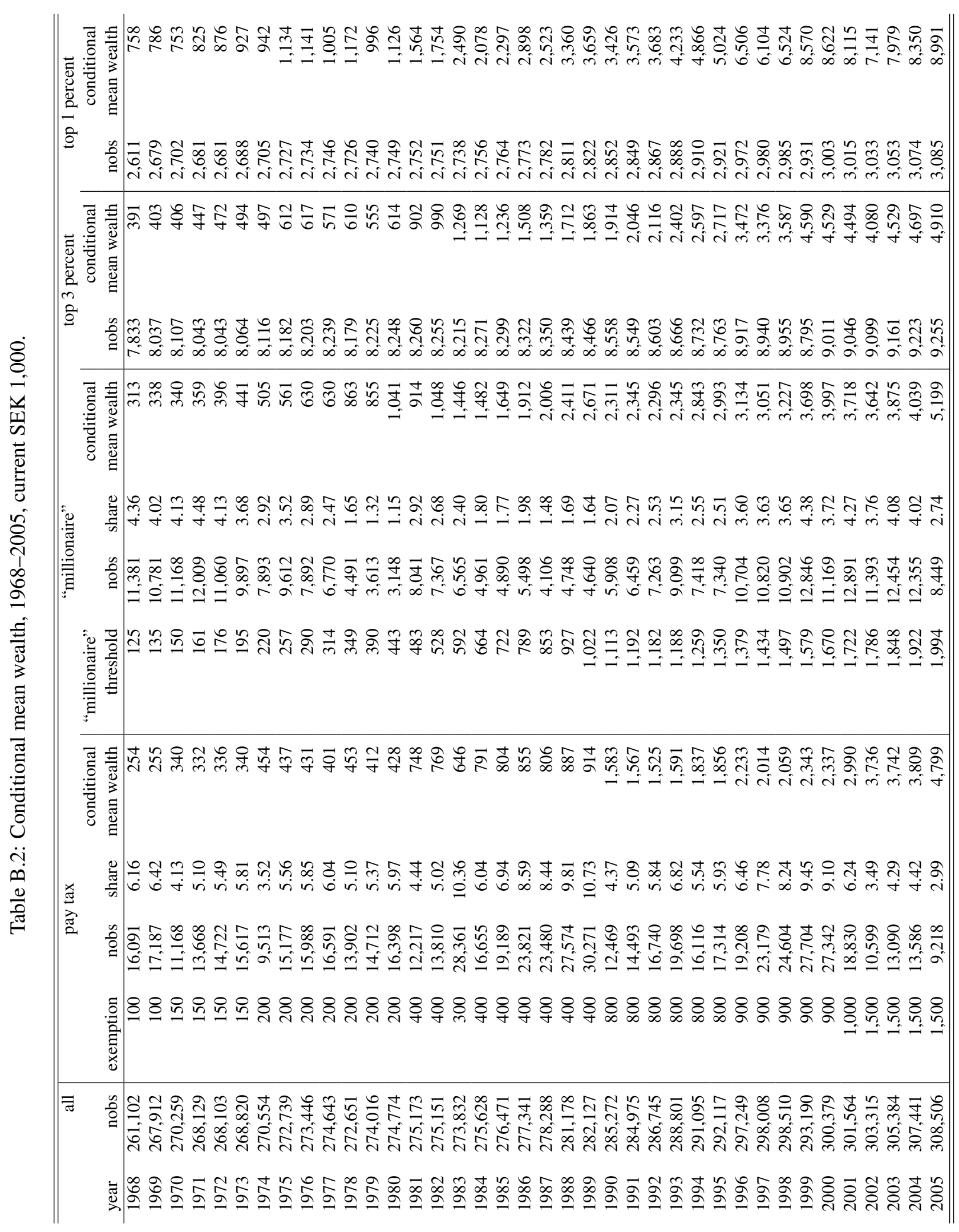




\section{Comparison with logit models}

This appendix presents additional auxiliary results. These results are useful to establish whether our sample selection for the conditional samples (in particular the restrictions that both $T_{i} \geq 30$, and that there be variation in the dependent variable over time for a given individual household) employed in Tables 4 and 6 leads to any biases. We illustrate this for the absolute threshold ("millionaires"). Results for the top three percent sample are similar.

Recall that to be able to calculate average partial effects for the fixed effects models, we need to rely on estimators that do not condition out the fixed effects, but rather allow estimating them. Estimation by way of dummy variable approaches is a viable route to do so, if the time series at the individual level are long enough. ${ }^{25}$ While the restriction $T_{i} \geq 30$ is arbitrary, we can compare the coefficient estimates we obtain with those from a conditional logit model. The latter only imposes mild restrictions on the required length of the time series $\left(T_{i} \geq 2\right)$. We can estimate dummy-variable binary choice models under a logit and under a probit functional form assumption, maximizing a standard likelihood function (see Greene, 2004, for details on implementation).

The functional form differences between logit and probit in themselves give rise to different coefficient estimates because of differences in scale that we correct for in the Table displayed below. Otherwise, we expect logit and probit dummy variable estimates to be close to each other, and close to the conditional logit estimates.

Indeed, as Table C. 1 shows, for each sample restriction, $T_{i} \geq 30, T_{i} \geq 20$, or $T_{i} \geq 2$, we find coefficient estimates from the different models that are very similar to each other. Whereas this finding is very reassuring for the case $T_{i} \geq 30$, the comparison at $T_{i} \geq 2$ is also very favorable to the fixed effects dummies probit estimator. Simulation assessments exist in the literature to gauge the size of potential biases of the dummy-variables approach. Our comparison using actual data suggests that the biases on coefficient estimates are minor, however, even for $T_{i} \geq 2$, and assuming the conditional logit estimates are always consistent.

The comparison across samples, as we go down from $T_{i} \geq 30$ to $T_{i} \geq 2$, is a little less favorable, but even here we find that the large majority of coefficient estimates is not very much affected by variation in sample size. Perhaps one of the largest differences concerns the coefficients on age polynomials that are very important to our study. However, plotting the implied age profiles shows that there is mainly a level shift implied between all models, not a noticeable difference in shape or curvature.

The very last column in Table C. 1 also displays the coefficient estimates underlying the first column in Table 2, where we also lift the restriction that there be any change in the dependent variable for a given individual. With the exception

\footnotetext{
${ }^{25}$ Else, we might face an incidental parameters problem, see Neyman and Scott (1948) and Greene (2004).
} 
of a few demographics, the estimates are quite similar to those in the next-to-last column that still does impose such a restriction.

Remaining differences in coefficient estimates between sample-lengths can be explained by households that are observed for a longer time period having a higher probability of being observed at least once to be wealthy than those observed for shorter periods. This observability is slightly correlated with some of our observables (for instance the number of children at different ages). The difference are not due to self-selection (agent's choice), however. 


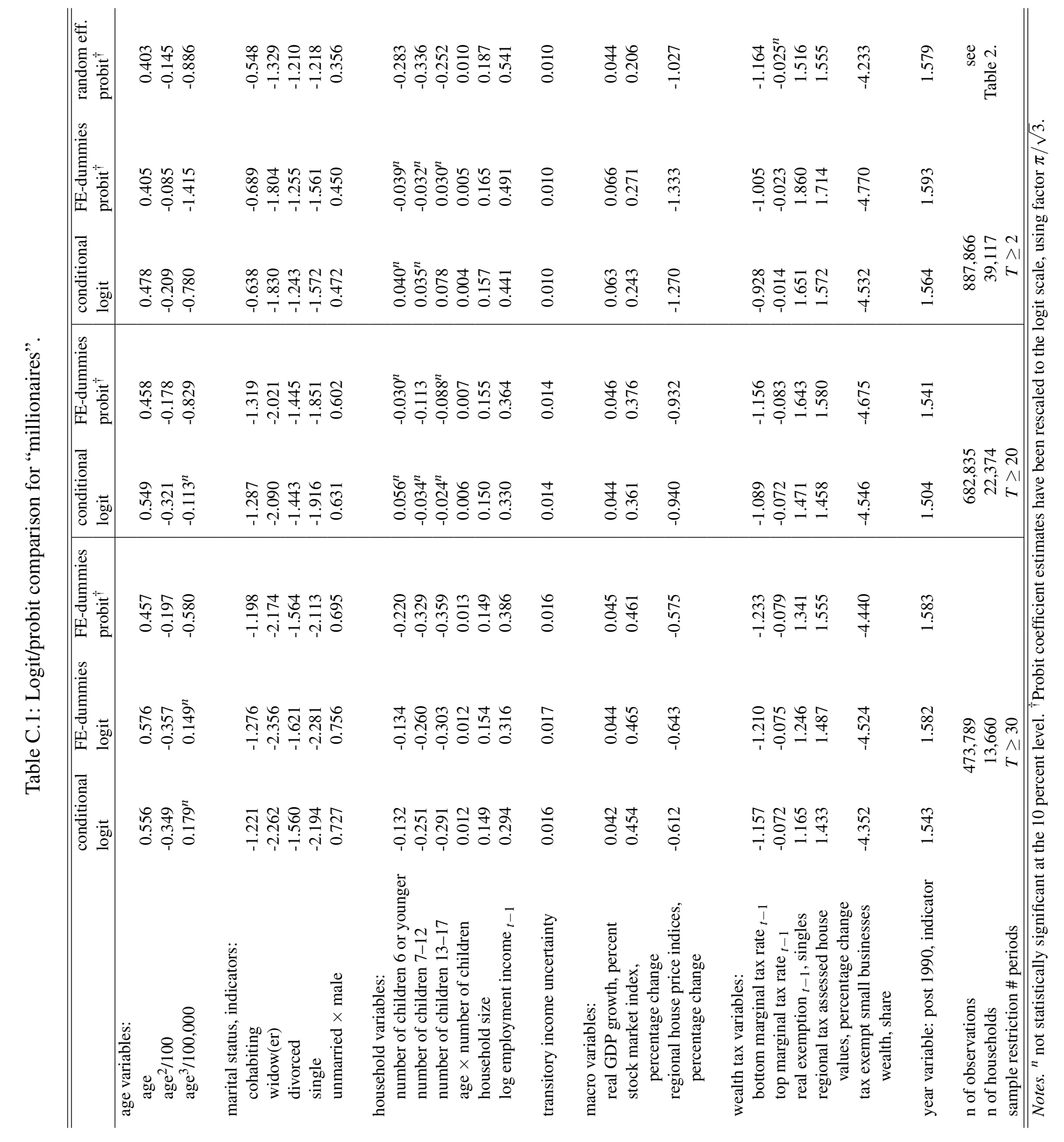

